\title{
Ionic liquid electrolytes in electric double layer capacitors
}

\author{
Li Yin, Shu Li, Xiaohong Liu ${ }^{*}$ and Tianying Yan
}

\begin{abstract}
Electric double layer capacitors (EDLCs), which store free charges on the electrode surface via non-Faradaic process, balanced by the electric double layer on the electrolyte side, exhibit excellent cycle stability and high power density. Though EDLCs are considered as promising energy storage devices, the charges stored on the electrode surface in EDLCs are much lower than those in batteries. Ionic liquids (ILs), as a new type of electrolytes in EDLCs, are capable to deliver high energy density, due to their excellent physicochemical properties and wide electrochemical window. In this review, we focus on the widely studied IL electrolytes for EDLCs, including pure ILs, IL/IL binary electrolytes, IL/organic solvent mixtures, as well as functionalized ILs, with attention on the relationship between the structures of different IL-based electrolytes and the energy storage properties in EDLCs. For imidazolium- and ammonium-based IL electrolytes which are most widely studied in EDLCs, the former generally have higher gravimetric specific capacitance, while the latter exhibit wider electrochemical window. The modifications of functional group substituted can be an effective strategy to enhance the gravimetric specific capacitance of the latter and thus improve the energy density of EDLCs.
\end{abstract}

Keywords: ionic liquids, electric double layer, capacitive performance, energy density, modification of IL electrolytes

\section{INTRODUCTION}

Ionic liquids (ILs), as “designer solvents”, are composed of bare ions with organic cations and organic or inorganic anions, which are liquids at room temperature. Most cations and anions are depicted in Fig. 1. ILs with remarkable physicochemical and electrochemical properties, such as high thermal stability, low vapor pressure, and wide electrochemical window, are considered as promising electrolytes for energy storage in electric double layer capacitors (EDLCs) [1-3]. In EDLCs, charges are stored on the 2-dimensional electrode surface via non-Faradaic process, which is considerably different from the batteries in which charges are stored in 3-dimensional electrode via Faradaic process. The charging/ discharging process in EDLCs is accompanied by the formation of electric double layer (EDL) in the electrolyte, while that process in batteries is generally accompanied by the intercalation/deintercalation and diffusion of ions in the electrode material $[4,5]$. Thus, EDLCs are capable of delivering higher power density with faster charging/ discharging rate than batteries. Additionally, the nonFaradaic process makes no degradation of electrode materials in EDLCs, and theoretically infinite cycling. Thus, EDLCs are able to provide excellent cycling stability (> 500,000 cycles) [6-8] and high power density (up to $10 \mathrm{~kW} \mathrm{~kg}^{-1}$ ) [7,9]. On the other hand, the charges stored on electrode surface in EDLCs are much lower than those in batteries. The relatively low energy density of EDLCs makes them difficult to replace batteries as energy storage devices in most practical applications at current stage [10].

The energy density of EDLCs is calculated by $E=1 / 2 C V^{2}$, in which $C$ is the capacitance of EDLCs and $V$ is the cell voltage. Thus, the energy stored in EDLCs increases as the square of $V$. Compared with the electrochemical window of aqueous electrolytes of $\sim 1 \mathrm{~V}$ [11-14] or organic electrolytes of $\sim 2.7 \mathrm{~V}$ [15], ILs exhibit wider electrochemical window, which can be up to $5 \mathrm{~V}$ [16]. Fig. 2 compares the cell voltage of aqueous electrolytes, organic electrolytes, and ILs, in which $\left[\mathrm{C}_{2} \mathrm{MIm}\right] \mathrm{BF}_{4}$ shows wider cell voltage $(\sim 3.5 \mathrm{~V})$ with higher energy density [17]. Thus, EDLCs with IL electrolytes have received

Institute of New Energy Chemistry, School of Materials Science and Engineering, National Institute for Advanced Materials, Nankai University, Tianjin 300350, China

* Corresponding authors (emails: xhliu@nankai.edu.cn (Liu X); tyan@nankai.edu.cn (Yan T)) 


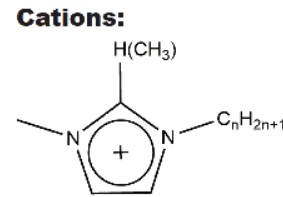

a II: $\left[\mathrm{C}_{\mathrm{n}} \mathrm{MIm}\right]^{+}$ $\mathrm{CH}_{3}:\left[\mathrm{C}_{\mathrm{n}} \mathrm{MMIm}\right]^{\prime}$<smiles>CCN1CCCC1</smiles>

b $\left[\mathrm{Pyr}_{1, \mathrm{n}}\right]$<smiles>C1CC[N+]2(C1)CCCC2</smiles>

c $[\mathrm{SBP}]^{+}$<smiles>CCN1CCCCC1</smiles>

d $\left[\operatorname{Pip}_{1, \mathrm{n}}\right]^{+}$<smiles>CC[N+](CC)(CC)CC</smiles>

e $\mathrm{N}:\left[\mathrm{N}_{\mathrm{klmn}}\right]^{-}$

Anions:

$(\mathrm{NC}) \mathrm{F}=\left.\right|_{\mathrm{F}(\mathrm{CN})} ^{\mathrm{B}(\mathrm{CN})}$

f $\mathrm{F}: \mathrm{BF}_{4}$

$\mathrm{CN}: \mathrm{B}(\mathrm{CN})_{4}$

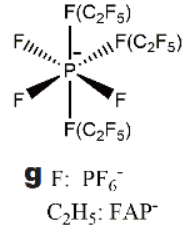

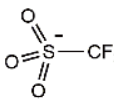

i $\mathrm{TF}^{-}$<smiles>N#CNC#N</smiles>

j $\mathrm{DCA}^{\circ}$

Figure 1 Chemical structure of several common cations and anions of ILs. Cations: (a) 1-alkyl-(2,)3-(di)methylimidazolium ([C $\left.{ }_{n} \mathrm{MIm}\right]^{+}$, $\left.\left[\mathrm{C}_{n} \mathrm{MMIm}\right]^{+}\right)$, (b) 1-alkyl-1-methyl-pyrrolidinium $\left(\left[\mathrm{Pyr}_{1, n}\right]^{+}\right)$, (c) spiro-(1,1')-bipyrrolidinium ([SBP $\left.]^{+}\right)$, (d) 1-alkyl-1-methylpiperidinium $\left(\left[\text {Pip }_{1, n}\right]^{+}\right)$, (e) tetraalkyl ammomium and phosphonium $\left(\left[\mathrm{N}_{k l m n}\right]^{+},\left[\mathrm{P}_{k l m n}\right]^{+}\right)$; Anions: (f) tetrafluoroborate and tetracyanoborate $\left(\mathrm{BF}_{4}{ }^{-}\right.$and $\left.\mathrm{B}(\mathrm{CN})_{4}^{-}\right),(\mathrm{g})$ hexafluorophosphate and tris(pentafluoroethyl)trifluorophosphate $\left(\mathrm{PF}_{6}{ }^{-}\right.$and $\left.\mathrm{FAP}^{-}\right)$, (h) bis(fluorosulfonyl)imide and bis(trifluoromethylsulfonyl)imide (FSI ${ }^{-}$and $\left.\mathrm{TFSI}^{-}\right)$, (i) trifluoromethanesulfonate $\left(\mathrm{TF}^{-}\right),(\mathrm{j})$ dicyanamide $\left(\mathrm{DCA}^{-}\right)$.
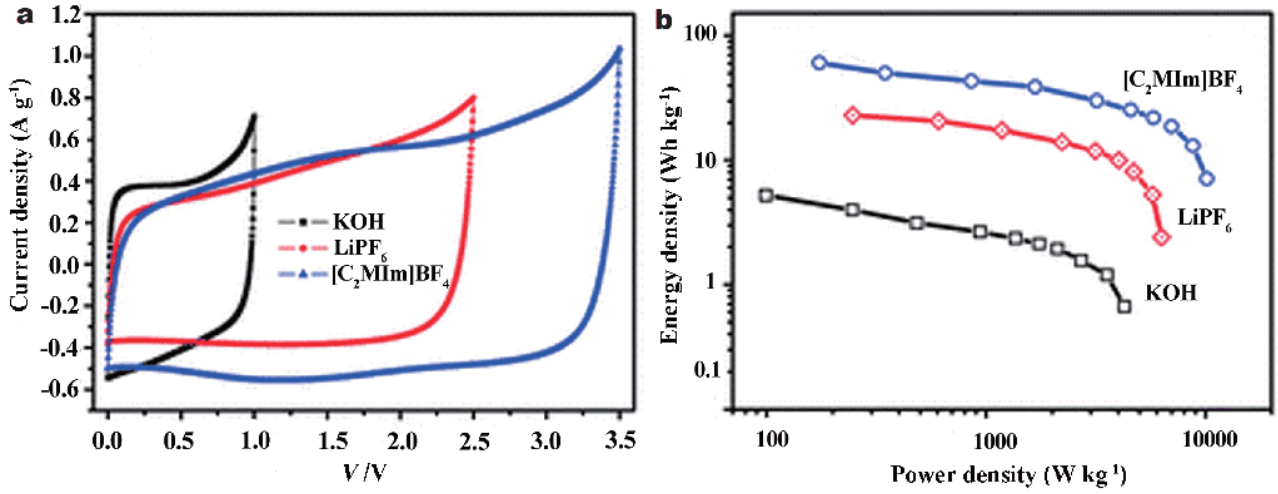

Figure 2 Comparison of (a) cell voltage and (b) Ragone plots in $\mathrm{KOH}, \mathrm{LiPF}_{6} / \mathrm{EC} /$ dimethyl ether (DME), and $\left[\mathrm{C}_{2} \mathrm{MIm}\right] \mathrm{BF}_{4}$. Reprinted with permission from Ref. [17]. Copyright 2013, Royal Society of Chemistry.

considerable attention, and are proved to be as energy storage devices with not only high power density and cycle stability, but also high energy density.

Apart from the cell voltage $V$, the energy density of EDLCs also grows with capacitance $C$, which is a complicated function that depends on electrodes, electrolytes, and the EDL thus formed. Nevertheless, it can be casted with the well celebrated Helmholtz model [18], i.e., $C=\frac{\varepsilon \varepsilon_{\theta} A}{d}$, in which $\varepsilon_{0}$ denotes the vacuum dielectric permittivity, $\varepsilon$ denotes the relative dielectric permittivity of electrolytes, $A$ is the effective specific surface area (SSA) of electrode that is accessible by electrolyte ions, and $d$ is considered as the effective EDL thickness, respectively [19]. For EDLCs in which the electrode charges are balanced by a thin EDL layer, $\varepsilon$ can be represented as optical dielectric permittivity $\left(\varepsilon_{\infty}\right)$ which is generally less than 2, contributed by the electronic polarization. Thus, the practical strategies of manipulation of EDLCs for higher $C$ are increasing $A$ of the electrode and decreasing $d$ of EDL.

A highly effective SSA can potentially ensure more charges storage on the electrode surface [20]. The pore size can also play an important role in determining the accessible surface for electrolyte ions to form EDLs [21]. Thus, the pore size distribution of electrode is important 
to improve the capacitive performance [22-24]. Additionally, the SSA is also greatly related to the pore geometry, such as slit, cylindrical and spherical [25]. The wettability of electrodes with IL electrolytes can facilitate ion diffusion in porous structure, and increase ion fluidity for EDL structure [26]. Therefore, the optimization of specific surface area, pore size distribution and conductivity of electrode materials can contribute to high specific capacitance, high stability and fast charging/discharging process of EDLCs, and thus towards higher energy density as well as higher power density [27-29]. Additionally, an optimized EDL thickness $d$ can screen the electric field on the electrode more efficiently and thus increase $C$. Lately, the incorporation of surface functional groups into electrodes is used to optimize intermolecular interactions between porous electrodes and electrolyte ions, which can improve pore ionophilicities and influence the dynamics of electrolytes [30-34]. However, this incorporating may introduce pseudo-capacitance and lead to some shortcomings, such as shortening cycling life and narrowing electrochemical window $[35,36]$. It should be emphasized that the rich fundamental thermodynamics is involved in EDL, which has been studied over the past 100 years [37,38], and is still an active field nowadays [39].

On the other hand, assuming ILs as concentrated electrolytes, anomalously long screening length demonstrates an important characteristic in them [40,41]. The strong ionic interaction of ILs results in the oscillation layering of counter-ions and co-ions (overscreening ef- fect), which increases the thickness of ionic layers and further reduces the capacitance [42]. ILs diluted with polar solvents and functionalized with organic group are proposed as efficient strategies to reduce the overscreening effect. Some functionalized ILs and common organic solvents are described in Fig. 3.

In this review, we focus on the widely studied IL electrolytes for EDLCs, including pure ILs, IL/IL binary electrolytes, IL/organic solvent mixed electrolytes, as well as functionalized ILs, with attention on the relationship between the structures of electrolyte ions and the energy storage properties in EDLCs.

\section{ELECTRIC DOUBLE LAYER AND DIFFERENTIAL CAPACITANCE}

Fundamental understanding of EDL structures dependent on the electrolyte ions is important for facilitating the applicability in EDLCs. Capacitance-potential relationship, namely, differential capacitance $\left(C_{\mathrm{d}}\right)$ is probed to better understanding the EDL structure and properties of IL/electrode interface [43-45]. Using Helmholtz model, the voltage-dependent EDL thickness can be probed as $\frac{1}{d(V)}=\frac{C_{\mathrm{d}}(V)}{\varepsilon \varepsilon_{0}}$. The measured $C_{\mathrm{d}}$ is equivalent to the effective EDL thickness $d$, which is a function of the polarized potential.

Experimentally, EDL structures may be probed by $C_{\mathrm{d}}$ using electrochemical impedance spectroscopy (EIS) technique. An impedance model for SCs consists of three regions: (i) the semi-circle at high frequency indicates the

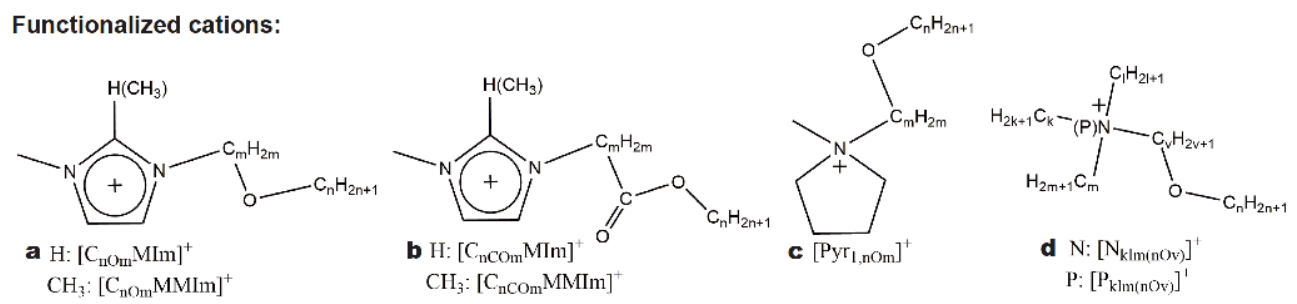

Organic solvents:

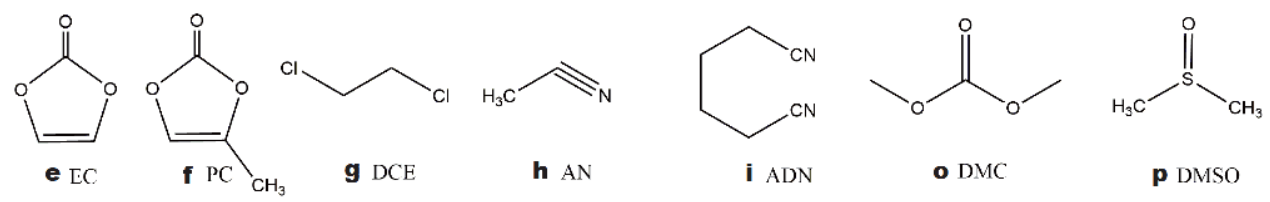

Figure 3 The structure of functionalized cations and common organic solvents. Functionalized cations: (a) 1-alkoxyalkyl-(2,)3-(di)methylimidazolium $\left(\left[\mathrm{C}_{\mathrm{nOm}} \mathrm{MIm}\right]^{+},\left[\mathrm{C}_{\mathrm{nOm}} \mathrm{MMIm}\right]^{+}\right)$, (b) 1-alkylcarboxyalkyl-(2,)3-(di)methylimidazolium $\left(\left[\mathrm{C}_{\mathrm{nCOm}} \mathrm{MIm}^{+},\left[\mathrm{C}_{\mathrm{nCOm}} \mathrm{MMIm}\right]^{+}\right),(\mathrm{c})\right.$ 1-alkoxyalkyl-1-methylpyrrolidinium $\left(\left[\mathrm{Pyr}_{1, \mathrm{nOm}}\right]^{+}\right)$, (d) ether-functionalized tetraalkyl ammonium and phosphonium $\left(\left[\mathrm{N}_{\mathrm{klm}(\mathrm{nOv})}\right]^{+},\left[\mathrm{P}_{\mathrm{klm}(\mathrm{nOv})}\right]^{+}\right)$. Organic solvents: $(\mathrm{e})$ ethylene carbonate (EC), (f) propylene carbonate (PC), (g) 1,2-dichloroethane (DCE), (h) acetonitrile (AN), (i) adiponitrile (ADN), (o) dimethyl carbonate (DMC), (p) dimethyl sulfoxide (DMSO). 
charge transfer resistance formed at the electrolyte/electrode interface; (ii) the mid-frequency Warburg impedance for EDLCs may result from the surface diffusion of the adsorbed ions and the diffusion within narrow pores; (iii) low-frequency capacitive behavior [46]. In comparison to complex impedance (Nyquist) representation, complex capacitance (Cole-Cole) plot is suggestive for understanding the charging/discharging with the separated capacitive processes. Fig. 4a shows a schematic EDL structure against a negatively charged planar electrode. Correspondingly, an ideal resistor-capacitor (RC) series circuit is adopted to represent EDL formation, along with the relaxation process appearing in the Cole-Cole plot shown in Fig. 4b, in which the complex capacitance is used to describe the EDL charging processes. As shown in Fig. $4 \mathrm{c}$ and d, $C_{\mathrm{d}}(V)$ clearly demonstrates that two capacitive processes take place on sub-millisecond time scale for the fast capacitive process and sub-second time scale for the slow capacitive process, respectively. In Fig. 4c, the Cole-Cole spectrum was fitted by $C(V, f)-C_{\infty}=\sum_{n=1}^{3} \frac{C_{\mathrm{Cole}, n}-C_{\infty}}{1+(j 2 \pi f \tau)^{\alpha_{\mathrm{Cole}, n}}}$, in which $C_{\infty} \cong 0$ denotes bulk capacitance which is negligible, and $0<\alpha_{\text {Cole, } n}$ $\leq 1$, where $\alpha_{\mathrm{Cole}, n}=1$ denotes the ideal capacitance process [47]. It is notable that the fast capacitive process is commonly attributed to the Debye relaxation for the EDL charging $[48,49]$, while the slow process is still under debates. For instance, the slow process was described as a slow Havriliak-Negami (HN) relaxation in Fig. 4d [49]. Roling et al. [47,48,50-52] suggested the slow process on the time scale of second may be related to structural reconstructions of the metal electrode surface and/or ion redistributions in the strongly bound ion-layer, which has been demonstrated by in-situ scanning tunneling microscopy (STM) [53,54]. Anderson et al. [55] attributed the slow process to the adsorption capacitance of the ions, while Pajkossy et al. [56] attributed the slow process to the dynamics of anions/cations replacement in the com-
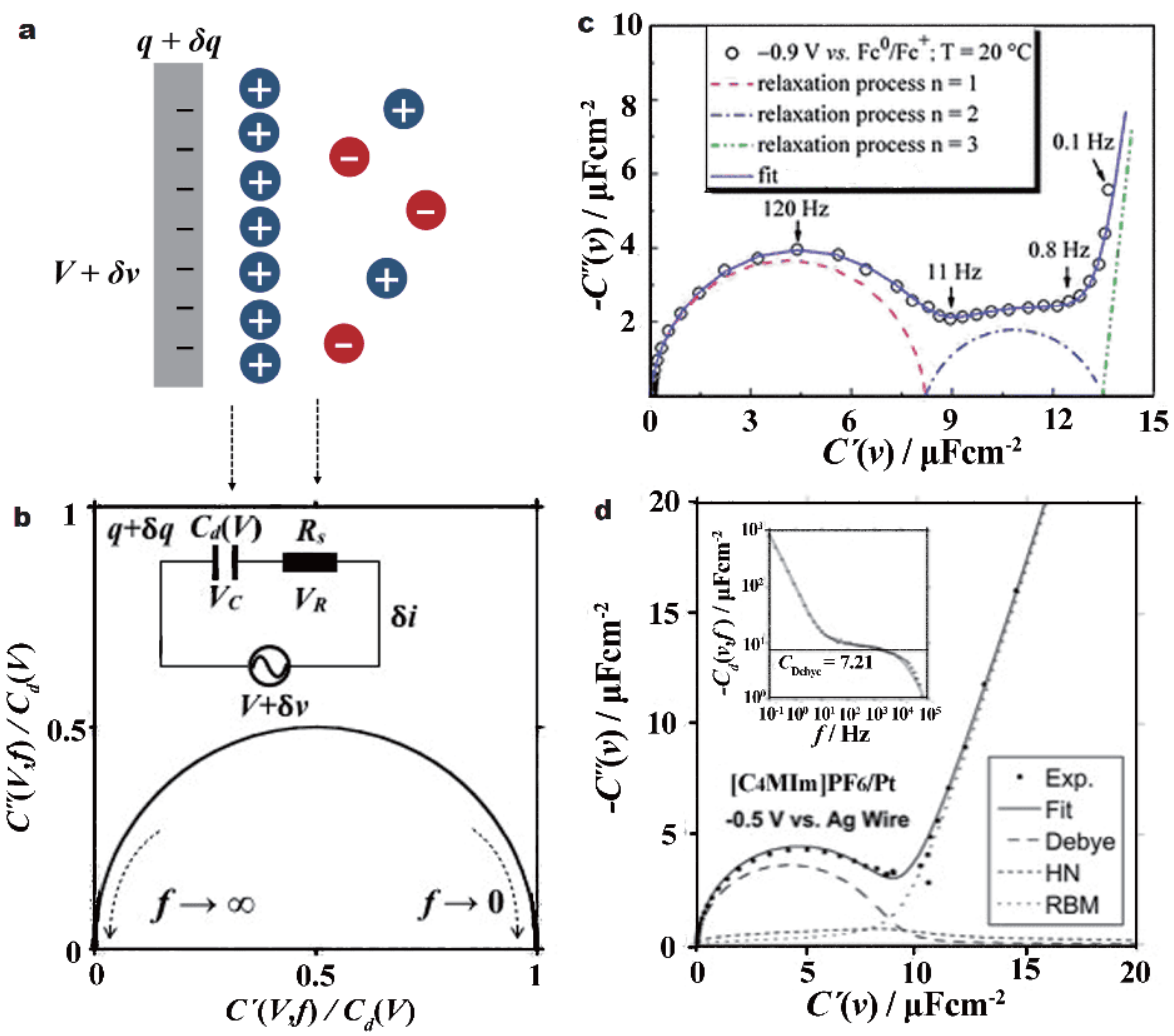

Figure 4 (a) EDL for a negatively charged planar electrode at fixed voltage $(V)$ and the accumulated charge $(q)$ at time $t$, which is balanced by counter-ions in electrolytes. (b) RC series circuit representation (inset) of EDL in (a), in which $C_{\mathrm{d}}$ denotes EDL capacitance, and $R_{\mathrm{s}}$ denotes the solution resistance. (c) Complex capacitance of $\left[\mathrm{Pyr}_{1,4}\right] \mathrm{TFSI} / \mathrm{Au}(111)$ electrode measured at $V=-0.9 \mathrm{~V} v \mathrm{vs} \mathrm{Fc}^{0} / \mathrm{Fc}^{+}$with EIS. Reprinted with permission from Ref. [47]. Copyright 2012, Royal Society of Chemistry. (d) Complex capacitance of $\left[\mathrm{C}_{4} \mathrm{MIm}\right] \mathrm{PF}_{6} / \mathrm{Pt}$ electrode measured at $V=-0.5 \mathrm{~V}$ vs. Ag wire with EIS. The inset of (d) shows $C_{\mathrm{d}}(V, f)$ with both EIS measurements (dot) and fits (solid line). Note that for ideal RC series in (b) with only Debye relaxation, $C_{\text {Debye }}$ is constant across the whole frequency window (dashed line). Reprinted with permission from Ref. [49]. Copyright 2018, Elesiver. 
pact layer. Although the physical models proposed by Roling et al. and Pajkossy et al. are based on general knowledge about electrochemical interface in ILs, their validation requires more precise structural information obtained by other approaches. Based on the results of insitu STM and atom force microscopy (AFM), Li et al. [57] revealed that the EDL was formed by three charged interior layered structures, while strong adsorption was absent in the interface. Meanwhile, an electric equivalent circuit involving different capacitance processes of different time scales was proposed, and the slow process may be due to the hindrance of reorientation and/or redistribution of ions in the more ordered and robust inner layer region. Though the origin of the slow capacitive process is still not clear, some recent studies attributed the fast capacitive process to the EDL formation [49,52].

Fig. 5 shows the $C_{\mathrm{d}}$-potential relationship and relaxation time-potential relationship of $\left[\mathrm{C}_{2} \mathrm{MIm}\right] \mathrm{TFSI}$ and $\left[\mathrm{C}_{4} \mathrm{MIm}\right] \mathrm{PF}_{6}$ on $\mathrm{Au}$ electrode, in which $C_{\mathrm{d}}$ was obtained by fitting against the full EIS spectra. The range of $C_{\mathrm{d}}$ of about $4-20 \mu \mathrm{F} \mathrm{cm}^{-2}$ is typical for most ILs [58]. The variation of $C$ with voltage reflects the different potential dependent EDL structure, or the voltage dependent EDL thickness. Since $\alpha>0.9$ at all voltage, the fast capacitive process, which is attributed to the formation of EDL, is close to the ideal Debye relaxation, and may be represented by RC series in Fig. $4 \mathrm{~b}$. It is also notable that $C_{\mathrm{d}}$ curves of the two ILs in Fig. 5 are in the same range, while $\tau_{\text {Cole }}$ of $\left[\mathrm{C}_{4} \mathrm{MIm}\right] \mathrm{PF}_{6}$ is an order of magnitude higher than that of $\left[\mathrm{C}_{2} \mathrm{MIm}\right] \mathrm{TFSI}$. Since $\tau=R_{\mathrm{s}} C_{\mathrm{d}}$, the solution resistance of $R_{\mathrm{s}}$ of the former is an order of magnitude higher than that of the latter, and the charging/discharging of $\left[\mathrm{C}_{2} \mathrm{MIm}\right] \mathrm{TFSI}$ is much faster than that of $\left[\mathrm{C}_{4} \mathrm{MIm}\right] \mathrm{PF}_{6}$. Thus, much information of EDL is probed with EIS.

Fig. 6 shows the $C_{\mathrm{d}}$ of widely studied imidazolium- and ammonium-based ILs $\left(\left[\mathrm{C}_{2} \mathrm{MIm}\right] \mathrm{BF}_{4}, \quad\left[\mathrm{C}_{2} \mathrm{MIm}\right] \mathrm{TFSI}\right.$, $\left[\mathrm{N}_{1114}\right]$ TFSI, $\left[\mathrm{N}_{1888}\right]$ TFSI), the ether group functionalized ammonium-based IL ([N $\left.\mathrm{N}_{122(102)}\right]$ TFSI), as well as IL/organic solvent mixtures containing imidazolium-based IL $\left(\left[\mathrm{C}_{2} \mathrm{MIm}\right] \mathrm{TFSI}\right)$ and acetonitrile (AN) with glassy carbon (GC) electrode. It is notable that GC electrode may be
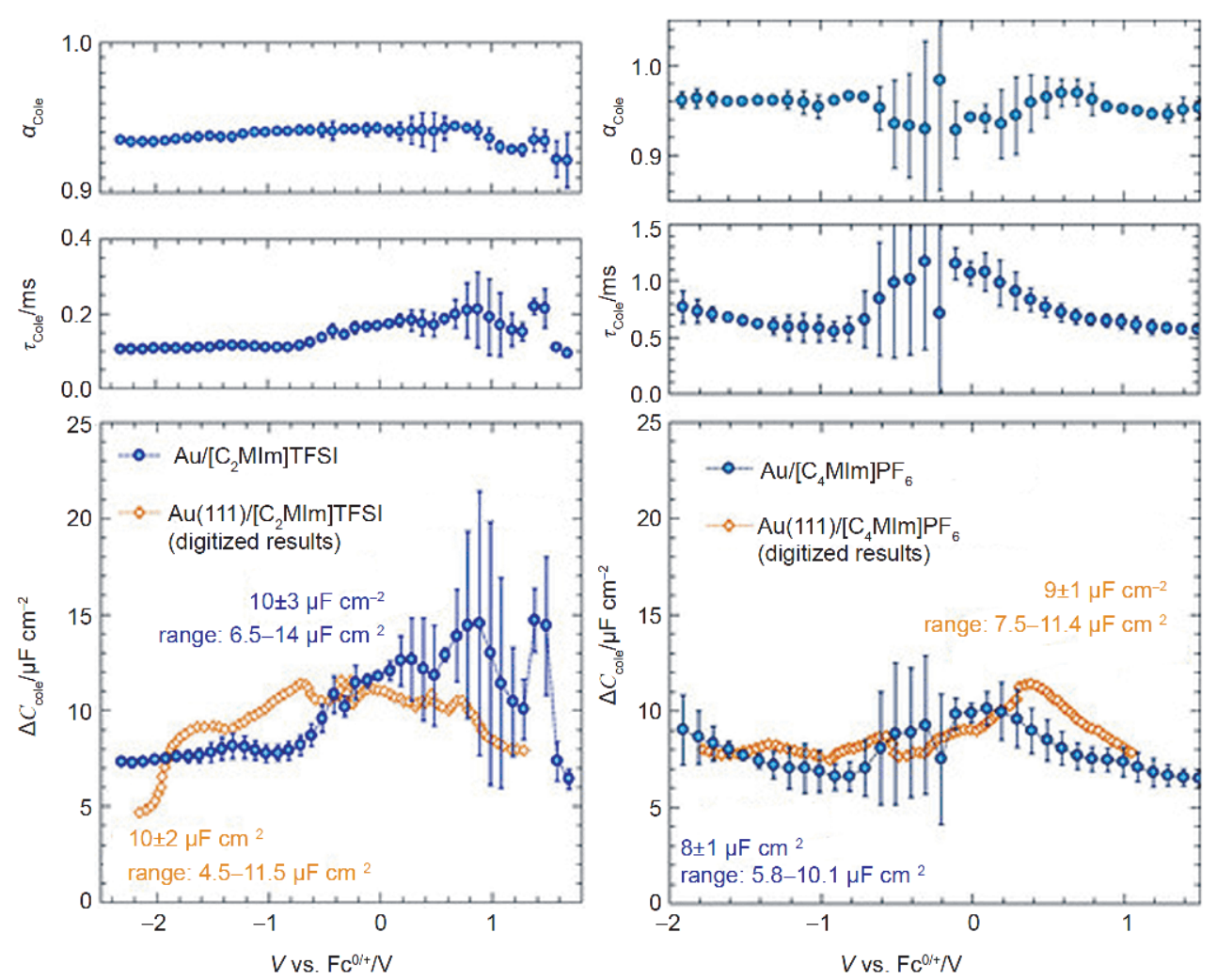

Figure $5 C_{\mathrm{d}}$ curves of $\left[\mathrm{C}_{2} \mathrm{MIm}\right] \mathrm{TFSI}$ and $\left[\mathrm{C}_{4} \mathrm{MIm}\right] \mathrm{PF}_{6}$ on Au electrode. $C_{\mathrm{d}}$ was fitted against complex capacitance of full EIS spectrum with a ColeCole relaxation (Fig. $4 \mathrm{c}$ ) and a constant phase element (CPE) for low frequency region $(<20 \mathrm{~Hz})$, and $C_{\mathrm{d}}=C_{\text {Cole }}$ for the fast Cole-Cole relaxation of sub-millisecond time scale. The top plots show $\alpha_{\text {Cole }}$ is in the range between 0.9 and 1.0, which is close to the ideal Debye relaxation ( $\left.\alpha=1\right)$; the middle plots show that the Cole-Cole relaxation is on the sub-millisecond time scale; the bottom plots compare the $C_{\mathrm{d}}$ reported by the same authors in two different studies. Reprinted with permission from Ref. [52]. Copyright 2018, American Institute of Physics. 

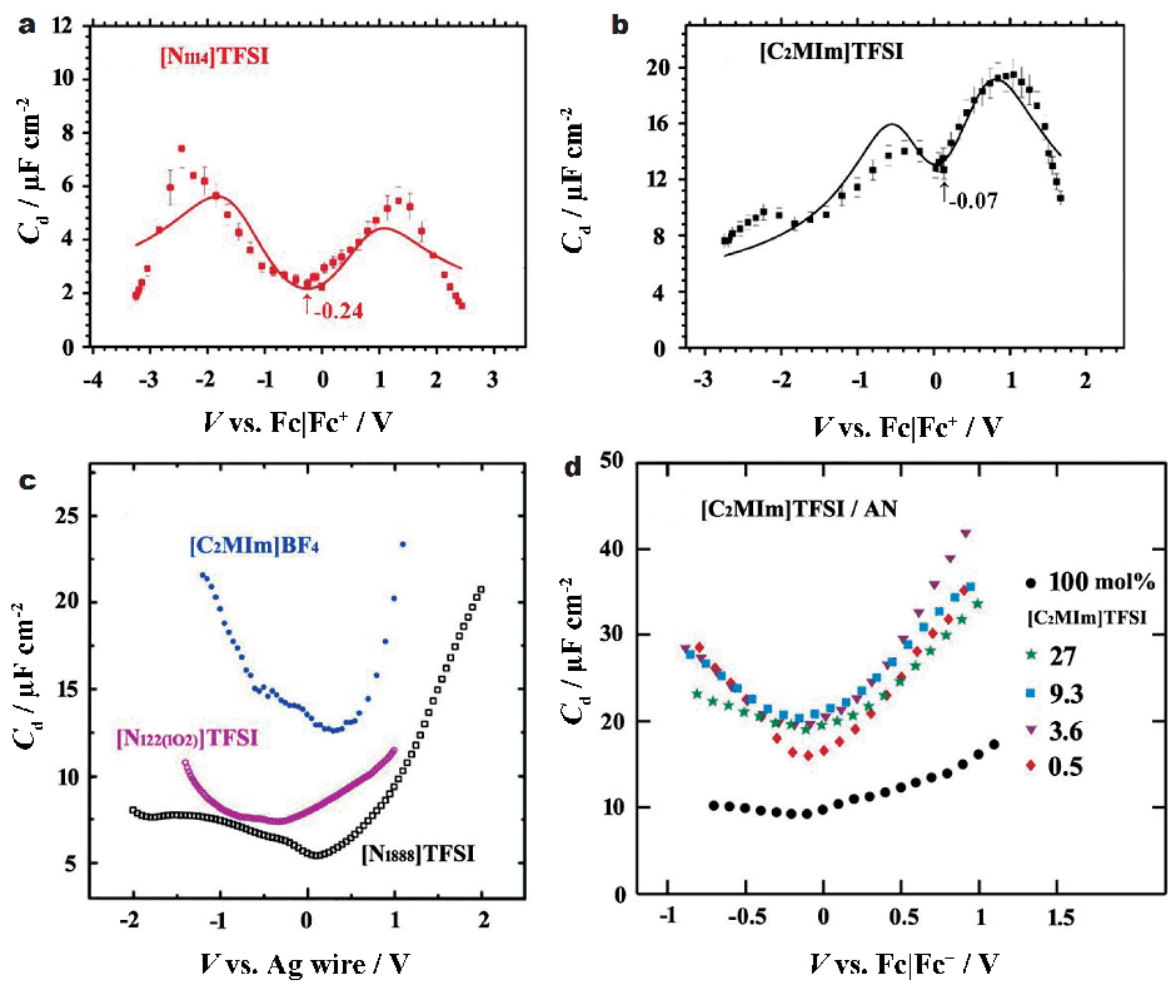

Figure 6 Differential capacitance measured on the GC electrode using different types of IL electrolytes. (a) $\left[\mathrm{N}_{1114}\right] \mathrm{TFSI}$ with a $5 \mathrm{~V}$ electrochemical window and (b) $\left[\mathrm{C}_{2} \mathrm{MIm}\right] \mathrm{TFSI}$ with a $4.3 \mathrm{~V}$ electrochemical window. The measurements (dots) were performed with complex capacitance of EIS spectrum based on the frequency range of $100 \mathrm{mHz}-500 \mathrm{kHz}$. The point of zero charge (PZC) is denoted by the arrow. Reprinted with permission from Ref. [16]. Copyright 2018, the Royal Society of Chemistry. (c) $C_{\mathrm{d}}$ of $\left[\mathrm{C}_{2} \mathrm{MIm}\right] \mathrm{BF}_{4},\left[\mathrm{~N}_{122(102)}\right] \mathrm{TFSI}$ and $\left[\mathrm{N}_{1888}\right] \mathrm{TFSI}$, measured with single frequency EIS at $200 \mathrm{~Hz}$. Reprinted with permission from Ref. [61]. Copyright 2009, American Chemical Society. (d) $C_{d}$ of [C 2 MIm]TFSI/AN mixtures with different mole concentrations of [ $\left.\mathrm{C}_{2} \mathrm{MIm}\right] \mathrm{TFSI}$, measured with single frequency EIS test at $46 \mathrm{~Hz}$. Reprinted with permission from Ref. [62]. Copyright 2015, American Chemical Society. The solid curves in (a) and (b) denote the fitting against a mean-field theory [63].

considered as a prototypical electrode for the EDLCs with porous carbon electrode but flat electrode surface to explore the EDL on the electrolyte side for the $C_{\mathrm{d}}$ measurement. Thus, EDL structure is manifested in the $C_{\mathrm{d}}$ curves, and it is notable that different sizes and chemical natures of cations and anions of ILs play a role in the formation of EDL. Here, caution should be addressed on the $C_{\mathrm{d}}$ curves reported by different research groups, such as the manner to determine $C_{\mathrm{d}}$, purity and compositions of ILs and a different electrochemical window that the measurements were performed. Such ambiguity is reflected in comparing $C_{\mathrm{d}}$ of neat $\left[\mathrm{C}_{2} \mathrm{MIm}\right] \mathrm{TFSI}$ in Fig. 6b (camel-shaped) and $\mathrm{d}$ (U-shaped). Such shapes originate from the nature of different compositions of ILs on building EDL in response to the electrode polarization $[59,60]$. In Fig. 6b, $\left[\mathrm{C}_{2} \mathrm{MIm}\right] \mathrm{TFSI}$ exhibits a higher capacitance at anodic polarization, which is screened by anion, $\mathrm{TFSI}^{-}$. In contrast, $\left[\mathrm{N}_{1114}\right]$ TFSI displays a higher capacitance at cathodic polarization than anodic polarization in Fig. 6a. Comparing Fig. $6 \mathrm{a}$ and b, the $C_{\mathrm{d}}$ in
$\left[\mathrm{C}_{2} \mathrm{MIm}\right]^{+}$is higher than that in $\left[\mathrm{N}_{1114}\right]^{+}$, although both with $\mathrm{TFSI}^{-}$anion. The results indicate that the cation plays an important role in determining the anion packing density on the anodic electrode surface. In addition, the ion size effect on the $C_{\mathrm{d}}$ can also be revealed in Fig. $6 \mathrm{c}$, in which $C_{\mathrm{d}}$ of $\left[\mathrm{C}_{2} \mathrm{MIm}\right] \mathrm{BF}_{4}$ is much higher than that of $\left[\mathrm{N}_{1888}\right]$ TFSI with large cationic size. On mixing with organic solvent $\mathrm{AN}, C_{\mathrm{d}}$ rises dramatically, as shown in Fig. 6d, owing to the effective dispersions of single ions in the electrolyte solution.

Table S1 summarizes the $C_{\mathrm{d}}$ of different ILs on different electrodes ( $\mathrm{Au}, \mathrm{Pt}, \mathrm{Hg}, \mathrm{GC})$. It should be kept in mind that single EIS frequency measurement at low frequency seems to overestimate $C_{\mathrm{d}}$, as shown in the inset of Fig. $4 \mathrm{~d}$, due to the reason that Debye relaxation associated with EDL charging/discharging process completes in submillisecond time scale. Though there is inconsistence in $C_{\mathrm{d}}$ even for the same ILs with the same electrodes, the general trend can be still derived from it. Nowadays, most ILs in capacitance studied can be classified as (1) 1,3- or 
1,2,3-alkylimidazolium; and (2) tetraalkyl ammonium (including pyrrolidinium) or phosphonium, with different anions, such as $\mathrm{PF}_{6}^{-}, \mathrm{BF}_{4}^{-}$and TFSI ${ }^{-}$(Fig. 1). Apart from that, there are also many studies on IL/IL mixtures, IL/organic solvent mixtures, and cationic functionalized ILs such as ether-substituted imidazolium and ammonium cations. The asymmetric $C_{\mathrm{d}}$ shape is reflected on the extreme values on the positive or negative polarizations, and $C_{\mathrm{d}}$ of most ILs is in the range of $4-20 \mu \mathrm{F} \mathrm{cm}$. Imidazolium-based ILs are the most studied class of ILs in capacitance with wide electrode chemical window, up to $4.5 \mathrm{~V}$ for $\left[\mathrm{C}_{2} \mathrm{MIm}\right] \mathrm{TFSI}$ on Pt electrode [64]. Ammonium-based IL ([ $\left.\left.\mathrm{N}_{1114}\right] \mathrm{TFSI}\right)$ has the widest electrochemical window up to $5.7 \mathrm{~V}$ on GC electrode [16]. Indeed, ammonium-based ILs, with wide electrochemical windows, are appropriate candidates to deliver high energy according to $E=1 / 2 C V^{2}$. It is notable that IL/organic solvent mixtures generally have higher $C_{\mathrm{d}}$ than neat ILs, but limited by its relatively narrow electrochemical window $(<3 \mathrm{~V})$. In addition, the $C_{\mathrm{d}}$ mainly characterizes the capacity of charge storage in response to a perturbation of applied polarization potential. The $C_{\mathrm{d}}$ plots possess detailed information of EDLs as a function of the polarized electrode potential, such as the feature of the overscreening effect and crowding effect. Compared with the planar electrodes, porous electrode materials possess diverse and irregular geometric structure, resulting in the distinct feature for the EDLs charging processes hided. Thus, for porous electrodes, the integral capacitance $\left(C_{\mathrm{i}}\right)$ is the most important observable of EDLCs, which characterizes the capacity of charge storage within an applied electrode potential vs. PZC. Therefore, both differential capacitance and integral capacitance characterize the capacity of charge storage, where $C_{\mathrm{i}}=\int_{\text {PZC }}^{V} C_{\mathrm{d}} \mathrm{d} V / \int_{\mathrm{PZC}}^{V} \mathrm{~d} V$. In brief, fundamental understanding of EDL structure by $C_{\mathrm{d}}$ curves with EIS technology can be used to improve the electrochemical performance of EDLCs with porous electrodes.

\section{CAPACITIVE PERFORMANCE FOR IL- BASED EDLCs}

\section{ILs with electrode materials for high performance of EDLCs}

Those carbon materials with high SSA in Table S2, including graphene, activated carbon, carbide-derived carbon, are widely used in EDLCs, which can enhance energy density. The experimental results and the related SSA (in Table S2) further confirm that charge storage in higher SSA leads to enhanced capacitive performance, and then provides higher energy density. Compared with the planar electrodes, the charging mechanisms of EDLCs based on porous carbons are more complex, such as counter-ions adsorption, co-ions desorption and ion exchange in the EDL layers adjacent to the carbons $[46,65,66]$. For example, the charge storage in subnanopores performs a function of the electrode voltage, which is mainly achieved by ion exchanging from co-ions desorption and counter-ions adsorption, entirely governed by co-ions desorption [67]. Meanwhile, the $C_{\mathrm{i}}$ is more appropriately instead of $C_{\mathrm{d}}$ for EDLCs in contact with porous electrodes. An IL-based EDLC is composed of two porous carbon electrodes with high SSA, isolated by a separator and impregnated with electrolytes [68]. A scheme of such symmetric EDLC is depicted in Fig. 7a, along with a representative 3-dimensional porous graphene material in Fig. $7 \mathrm{~b}$. With a cell voltage $(V)$ applied between the electrodes, cations of electrolytes accumulate on the cathode surface, while the anode surface attracts anions. Hence, an EDLC is equivalent to two capacitors of $C_{+}$and $C_{-}$in series, with $C_{+}$and $C_{-}$for the capacitance of the anode and cathode respectively, i.e., $\frac{1}{C}=\frac{1}{C_{+}}+\frac{1}{C_{-}}$.

The charges stored on anode $\left(Q_{+}\right)$and cathode $\left(Q_{-}\right)$ may be calculated via integration of $C_{\mathrm{d}}$ for the anodic and cathodic branch individually, i.e., $Q_{ \pm}=\int_{\mathrm{PZC}}^{V_{ \pm}} C_{\mathrm{d}}\left(V^{\prime}\right) \mathrm{d} V^{\prime}$, in which $C_{ \pm}=\frac{Q_{ \pm}}{V_{ \pm}-\mathrm{PZC}}$ [52]. Since $C_{\mathrm{d}}$ is asymmetric due to the different chemical nature of cations and anions, $C_{+}$is not necessarily equal to $C_{-}$. On the other hand, the stored charges are balanced, i.e., $Q_{+}=-Q_{-}$, so that the voltage on anode $\left(V_{+}\right)$and cathode $\left(V_{-}\right)$are not necessarily symmetric with respect to the bulk voltage, though the assembly of EDLC is symmetric.

It is notable that the areal specific capacitance $\left(C_{\mathrm{SSA}}\right.$, Table S2) does not indicate a linear relationship between the gravimetric specific capacitance and the increased SSA. The reason is that pore size distribution (PSD) is also important in determining the energy density of EDLCs, besides SSA [69]. Chmiola et al. [70] demonstrated that the capacitance firstly decreased with decreasing the pore size to less than twice of the counter-ion size, and then increased rapidly with further decreasing the pore size to approach to the counter-ion size, as shown in Fig. 7c. $C_{\mathrm{SSA}}$ normalized by the SSA depended on the pore size of electrode materials in $\left[\mathrm{N}_{2222}\right] \mathrm{BF}_{4} / \mathrm{AN}$ electrolytes. The pores size comparable to that of the counter-ions facilitated to enhance the areal specific capacitance, since the desolvated counter-ions by the lim- 
a

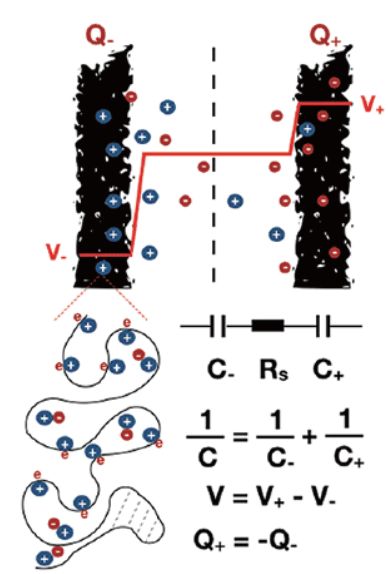

b

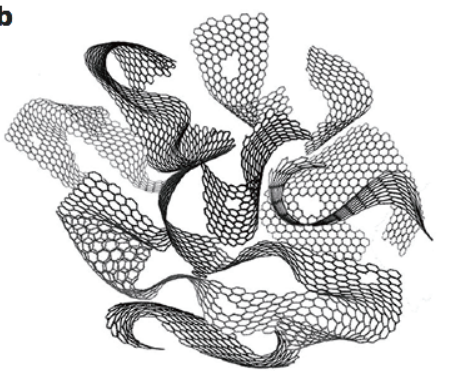

c

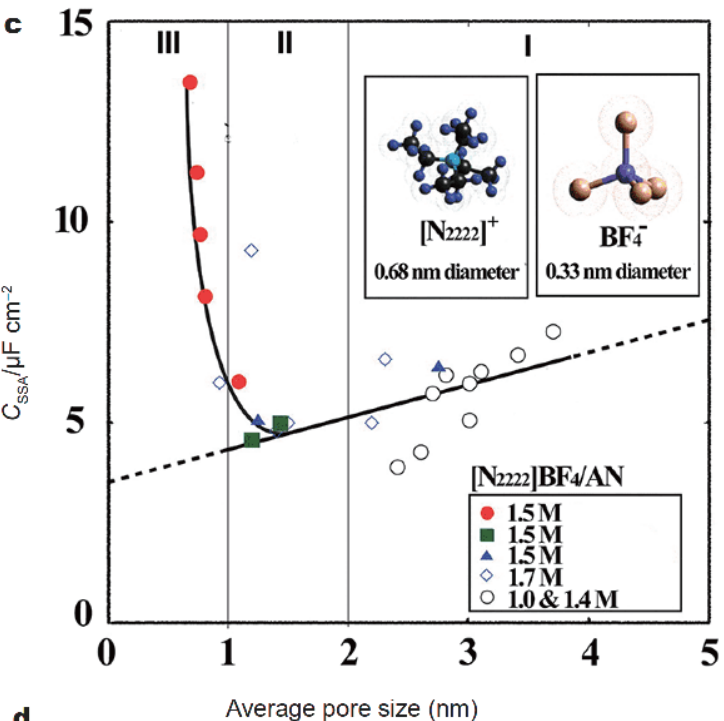

d

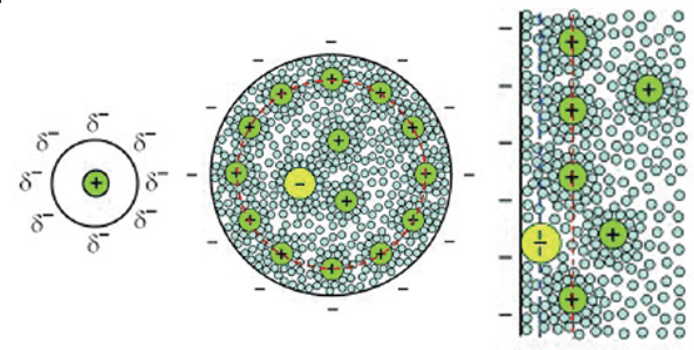

Figure 7 (a) A scheme of a symmetric EDLC with porous carbon electrodes, left: cathode, right: anode, vertical dashed line: separator. The red line denotes potential drop from anode to cathode. (b) A representative 3-dimensional model of porous graphene-based material with high SSA. Reprinted with permission from Ref. [79]. Copyright 2013, Nature Publishing Group. (c) Dependence of areal specific capacitance on the pore size of electrode composed of carbon nanotubes of different diameters with $\left[\mathrm{N}_{2222}\right] \mathrm{BF}_{4} / \mathrm{AN}$ electrolytes. This study highlights the importance of PSD in the capacitance performance. Reprinted with permission from Ref. [70]. Copyright 2006, American Association for the Advancement of Science. (d) Schematic diagrams of EDL charging in mircopores, mesopores, and macropores. Reprinted with permission from Ref. [71]. Copyright 2008, Wiley.

ited pore width may allow closer approach of the counterions to the electrode surface, resulting in the decreasing of EDLs thickness $d$. Furthermore, the pore curvature of electrodes also affects the capacitance of EDLCs [71]. When the charge stored in the micropores $(<2 \mathrm{~nm})$, counter-ions can link up along the pore axes, while the counter-ions can be adsorbed on the pore walls in mesopores $(2-50 \mathrm{~nm})$, as shown in Fig. $7 \mathrm{~d}$. In the macropores $(>50 \mathrm{~nm})$, the macropores electrode/electrolyte interface can be approximately by an EDL (in Fig. 7d). Namely, the pore geometry plays a significant role in the charge storage of EDLCs. By assuming that the pores are cylindrical, the counter-ions enter the micropores and link up to form electric wire-in-cylinder capacitor, which rationalizes an anomalous increase of $C_{\mathrm{SSA}}$ in subnanometer pore regime III of Fig. 7c. For mesopores, counter-ions enter pores and approach near the electrode surface to form electric double-cylinder capacitor, while the pore curvature effect is negligible for macropores. In addition, the $C_{\mathrm{SSA}}$ exhibits oscillatory behavior as a function of pore size with a broad distribution, since the measured $C_{\mathrm{SSA}}$ is averaged over pore size [72]. In contrast to the above mentioned endohedral nanopores, counterions approach the external surfaces of 0 -dimension onion-like carbon (OLC) and 1-dimension carbon nanotubes (CNTs) to form exohedral electric double-sphere capacitor and exohedral electric double cyclinder capacitor, respectively [73]. Feng et al. [74,75] studied the effects of electrode curvature on the charge storage in EDLCs based on ILs. They found that the $C_{\mathrm{SSA}}$ increased with increasing curvature and decreasing OLC size, in agreement with the theoretical prediction [73].

On the other hand, electrolytes also play an important role in the charge storage of EDLCs, and it is meaningful to understand the dynamics of charge storage of EDLCs. It was confirmed that the correlation between the elec- 
trolyte and the electrode is important in the IL-based EDLCs, such as a $\pi-\pi$ stacking structure formed by imidazolium-based ILs in contact with graphene electrode $[76,77]$. Especially, the semi-infinite diffusion within the bulk electrolyte does not affect the charge storage of EDLCs, while the main diffusion process in such electrostatic adsorption should be the surface diffusion near the electrode [46]. Jo et al. [78] investigated the charging dynamics of cyano-based ILs for EDLCs by molecular dynamics (MD) simulations. They revealed that the $C_{\mathrm{d}}$ maxima of all liquids resulted from the respective anions desorption. They subsequently reported that the charging dynamics of EDLCs was largely dependent on the co-ions desorption by MD simulations [76].

Influence of ionic composition of ILs on the performance Fig. $8 \mathrm{a}-\mathrm{c}$ demonstrate the effects of cations containing various alkyl side chain lengths and types on gravimetric specific capacitance. Owing to the increased size of cations, the gravimetric specific capacitance decreases with
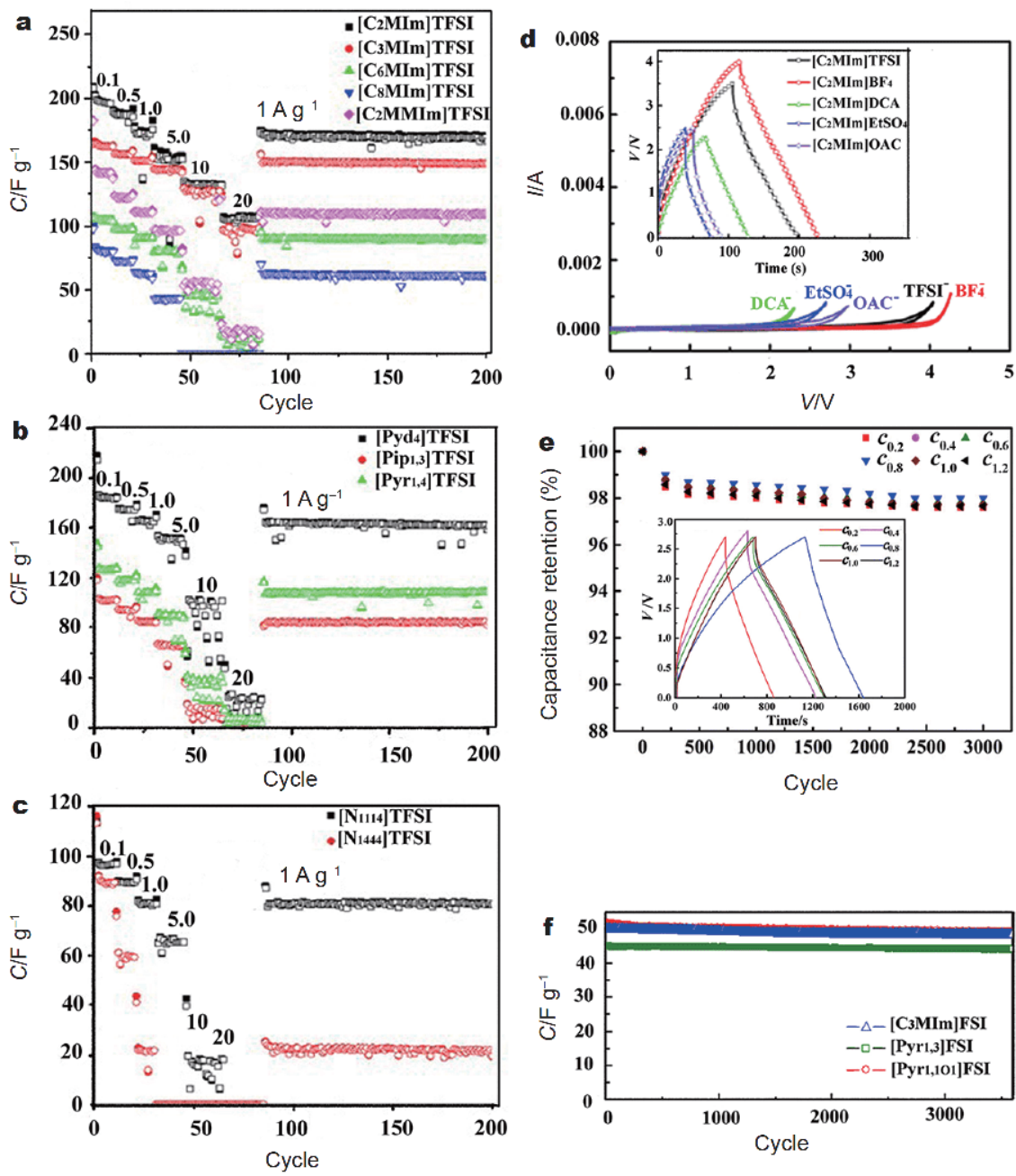

Figure 8 Comparisons of gravimetric specific capacitances using different IL electrolytes. (a-c) The effect of cationic sizes and types on the $C$ at different current densities. The cycle stability of (a) alkyl chain length in imidazolium-based ILs, (b) different types of cations with ring structure and (c) alkyl chain length in tetraalkyl ammonium-based ILs measured at a current density of $1 \mathrm{Ag}^{-1}$. Reprinted with permission from Ref. [97]. Copyright 2016, American Chemical Society. (d) The effect of anion types on the electrochemical windows and charging/discharging processes at a current density of $1 \mathrm{~A} \mathrm{~g}^{-1}$. Reprinted with permission from Ref. [83]. Copyright 2014, Wiley. (e) Cycle performance and galvanostatic charging/ discharging curve (inset) for $\left[\mathrm{C}_{2} \mathrm{MMIm}_{\mathrm{B}} \mathrm{BF}_{4} / \mathrm{AN}\right.$ mixed electrolytes under different concentrations at a constant current density of $0.02 \mathrm{Ag} \mathrm{g}^{-1}$ in the cell voltage from 0.0 to $2.7 \mathrm{~V}$. Reprinted with permission from Ref. [86]. Copyright 2019, Springer. (f) The effect of ether-functionalization on improving gravimetric specific capacitance for pyrrolidinium-based ILs at a current of $2.5 \mathrm{~mA} \mathrm{~cm}{ }^{-2}$. Reprinted with permission from Ref. [90]. Copyright 2016, Elsevier. The capacitance in $(\mathrm{a}-\mathrm{c})$ was reported as single electrode capacitance, while the capacitance in (f) was reported as cell capacitance. 
the longer alkyl side chain. The reason may be that the sieving effect of electrolyte ions decreases the concentration of counter-ions inside the pore with increasing the cationic size. On the other hand, as the increasement of alkyl tail in cations, the volumetric limitation reduces the favorability of the cationic orientation in the pore. The increased cationic size also decreases the utilization of the accessible surface area. Thus, $\left[\mathrm{C}_{2} \mathrm{MIm}\right] \mathrm{TFSI}$ exhibits the highest gravimetric specific capacitance compared with other imidazolium-based ILs with the common anion as shown in Fig. 8a. For ammonium cations, pyrrolidinium-based ILs exhibit a higher capacitance than tetraalkyl ammonium-based ILs. Spiro-(1,1')bipyrrolidinium cation ([SBP $]^{+}$, in Fig. 1c) has attracted interest in enhancing capacitance, owing to the increased pore accessibility and ionic packing density by the decreased ionic size [80-82]. For imidazolium-based ILs of $\left[\mathrm{C}_{2} \mathrm{MIm}\right]^{+}$with different anions in Fig. 8d, it can be seen that $\mathrm{BF}_{4}{ }^{-}$and $\mathrm{TFSI}^{-}$anions can be operated with higher cell voltage than the others, attributed to the higher oxide stability of anions containing fluorine [83]. Besides, the higher capacitance of ILs associated with $\mathrm{BF}_{4}{ }^{-}$may be attributed to its smaller anionic size. In the case of TFSI', $\left[\mathrm{C}_{2} \mathrm{MIm}\right]$ TFSI was reported to have a wider electrochemical window ranging from -1.6 to $2.4 \mathrm{~V}$ ( $v s$. $\mathrm{Ag}$ wire) [84]. The narrower cell voltage of $\mathrm{TFSI}^{-}$compared with $\mathrm{BF}_{4}^{-}$in Table S2 may be attributed to the lower capacitance contributed by $\mathrm{BF}_{4}^{-}$for a charge equilibrium system, which results in the decomposition of $\mathrm{TFSI}^{-}$when exceeding the electrochemical window. Owing to the higher cell voltage of $4 \mathrm{~V}$, the EDLC with $\left[\mathrm{C}_{2} \mathrm{MIm}\right] \mathrm{BF}_{4}$ electrolyte displays a maximum energy density of $46 \mathrm{~W} \mathrm{~h} \mathrm{~kg}^{-1}$ [85]. As a result, anions which are adsorbed on the positive electrodes play a key role in the charging/ discharging process.

\section{IL/organic solvent mixed electrolytes}

However, within the formation of EDL, overscreening and alternating layers of counter-ions and co-ions are governed by the strong ion-ion correlations in ILs, which hamper the optimization of EDL structure [42]. On the other hand, charging of the EDLC is not only dominated by the adsorption of the counter-ions, but also dependent on the desorption of co-ions adjacent to the electrode [76]. After introducing organic solvents, the enhanced ion diffusion results in shortening the characteristic time of fast charging/discharging time, and also enhances the capacitive performance of EDLCs owing to the high dielectric constant of organic solvent that disperses ions [49]. As demonstrated in Fig. 8e, the electrochemical performance can be improved by using appropriate ratio of IL diluted by polar organic solvents, in which $0.8 \mathrm{~mol} \mathrm{~L}^{-1}\left[\mathrm{C}_{2} \mathrm{MMIm} \mathrm{BF}_{4} / \mathrm{AN}\right.$ mixture achieves $98 \%$ capacitance retention and $142.6 \mathrm{~F} \mathrm{~g}^{-1}$ of gravimetric specific capacitance, respectively [86]. On the other hand, for the EDLC with IL/organic solvent mixture electrolytes, the highest reported cell voltage is $3.5 \mathrm{~V}[7,87-89]$. It is very difficult to further increase the cell voltage of this class of electrolytes. Thus, the relatively narrow electrochemical window and volatility inherent in organic solvents limit their usage in EDLCs. Meanwhile, the potential challenge for IL/organic solvent mixed electrolytes is that the solvation of ions may lower the ionic packing density and then limit the enhanced capacitance.

\section{Functionalized ILs}

It is of interest to note that the functionalized ILs, often with methylene group on the alkyl side chain of the cation replaced by an ether group, may take advantage of the merits of IL/organic solvent mixtures. An ether moiety is isoelectronic with methylene, but introduces an electronegative center on the cation with more delocalized charge than its alkyl counterpart. Such effect reduces ion pair interactions and may also alter the EDL structure, as the ether-functionalized side chain is repelled from the cathodic polarized electrode. According to the comparison in Fig. 8f, the functionalized cation $\left[\mathrm{Pyr}_{1,1 \mathrm{O} 1}\right]^{+}$retains higher capacitance of $206 \mathrm{~F} \mathrm{~g}^{-1}$ than that of the corresponding alkyl cation $\left[\mathrm{Pyr}_{1,3}\right]^{+}$, which reveals that the introducing of ether bond improves the capacitance compared with the cation without ether substitution [90]. The experimental results are further confirmed by the ammonium-based IL/organic solvent mixture electrolytes, where $\left[\mathrm{N}_{111(\mathrm{O} 1)}\right] \mathrm{BF}_{4} / \mathrm{AN}$ delivers a energy density up to $13.3 \mathrm{~W} \mathrm{~h} \mathrm{~kg}^{-1}$ comparable to $12.7 \mathrm{~W} \mathrm{~h} \mathrm{~kg}^{-1}$ in $\left[\mathrm{N}_{1113}\right] \mathrm{BF}_{4} / \mathrm{AN}$ [91]. Furthermore, the presence of functional group should be significant insight into the influence on the electrochemical window governed by both cathodic stability and anionic stability, as our key objective is to find appropriate electrolytes with wide cell voltage for high energy density of EDLCs. Despite an ether group in the cation may result in a decreased cathodic stability, which may be attributed to the reduction of the ether group at a more positive polarization potential, the ammonium-based ILs still contain wide electrochemical window, where $\left[\mathrm{Pyr}_{1,1 \mathrm{O} 1}\right] \mathrm{C}_{2} \mathrm{~F}_{5} \mathrm{BF}_{3}$ and $\left[\mathrm{Pyr}_{1,1 \mathrm{O} 2}\right] \mathrm{C}_{2} \mathrm{~F}_{5} \mathrm{BF}_{3}$ remain 5.27 and $5.22 \mathrm{~V}$, respectively [92]. On the other hand, ILs with ether groups favor an increase of the fluidity and conductivity [93]. Considering the influence of functional group into ILs and ionic 

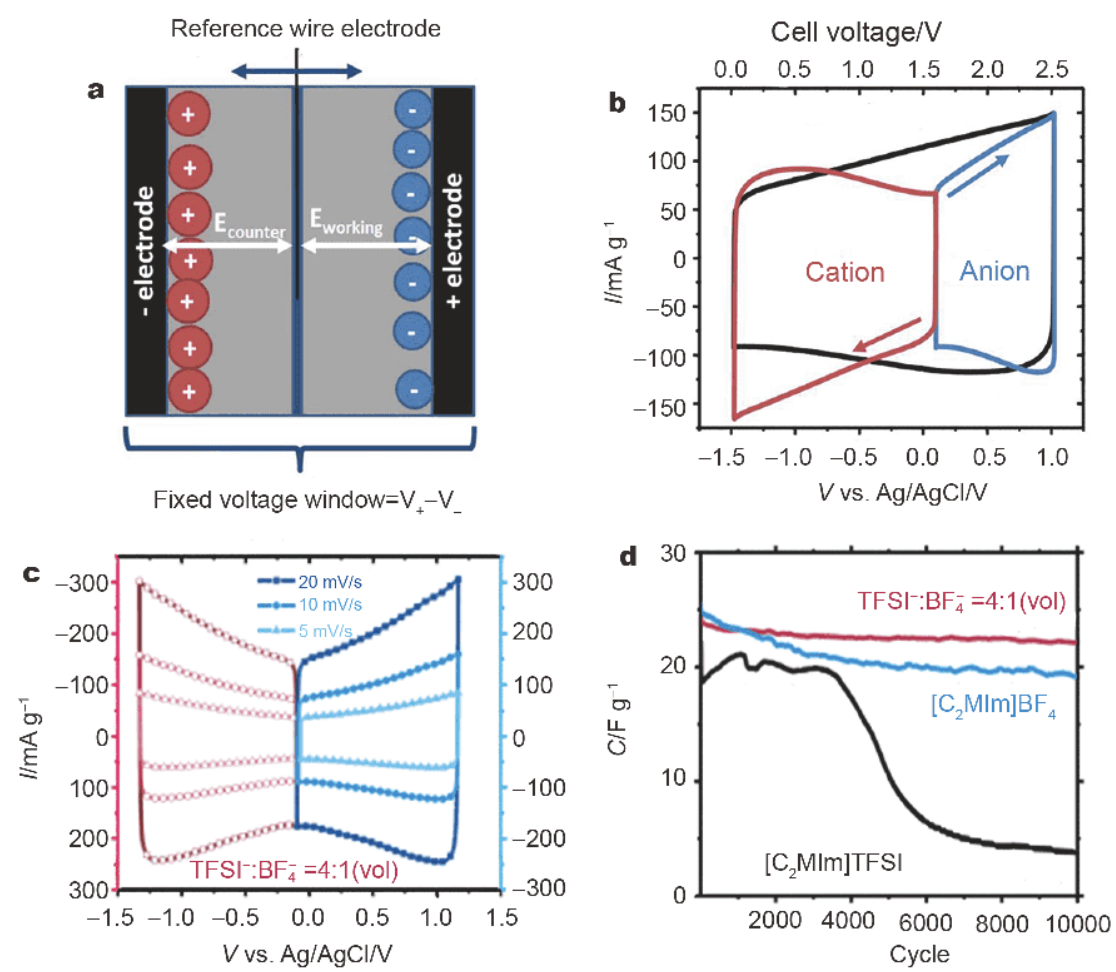

Figure 9 (a) Scheme of the 3-electrode setup used for testing the voltage on the electrodes in EDLC with applied cell voltage $V=V_{+}-V_{-}$, in which $V_{+}$ and $V_{-}$denote the voltage of anode and cathode, respectively, with respect to the reference electrode. (b) The corresponding cyclic voltammogram for the cell assembled with $\left[\mathrm{C}_{2} \mathrm{MIm}\right]$ TFSI for the entire cell (black), cathode (red), and anode (blue), with a cell voltage of $2.5 \mathrm{~V}$ and a scan rate $10 \mathrm{mV} \mathrm{s}$. The variation of the charges on the electrode with charging or discharging time $t$ is $Q(t)=\int_{0}^{t} I\left(t^{\prime}\right) \mathrm{d} t$. This figure clearly demonstrates the asymmetric EDLs established at the cathode and anode, though they are symmetric or identical in EDLCs. (c) Cyclic voltammograms for cells assembled with the mixture containing $\left[\mathrm{C}_{2} \mathrm{MIm}\right]$ TFSI with 20 vol\% $\left[\mathrm{C}_{2} \mathrm{MIm}\right] \mathrm{BF}_{4}$ at three different scan rates $\left(20,10,5 \mathrm{mV} \mathrm{s}{ }^{-1}\right)$. Cell voltage is $2.5 \mathrm{~V}$. (d) Gravimetric specific capacitance for cells assembled with $\left[\mathrm{C}_{2} \mathrm{MIm}\right] \mathrm{TFSI},\left[\mathrm{C}_{2} \mathrm{MIm}\right] \mathrm{BF}_{4}$, and $20 \mathrm{vol} \%\left[\mathrm{C}_{2} \mathrm{MIm}\right] / \mathrm{BF}_{4}$ mixtures at a constant current density of $2 \mathrm{~A} \mathrm{~g}^{-1}$ and applied cell voltage of 3.5 V. Reprinted with permission from Ref. [102]. Copyright 2015, Wiley.

compositions on capacitive performance, the aims are to design and optimize ILs for high capacitance and thus high energy density. Recently, oligomeric ILs with etherbridge have been investigated as electrolyte candidates for high capacitance, while their applicability is limited at low rate process due to the higher viscosity [94-96].

\section{IL/IL binary electrolytes}

In contrast to the highest cell voltage of $4 \mathrm{~V}$ for $\left[\mathrm{C}_{2} \mathrm{MIm}\right] \mathrm{BF}_{4}[85,98]$, the electrochemical windows of ammonium-based ILs are wider than that of the imidazolium-based ILs, as shown in Table S1. Besides, it is notable that cell voltages of EDLCs with different ILs in Table S2 are generally narrower than their individual electrochemical windows in Table S1. Therefore, utilizing the entire electrochemical windows is the significantly promising strategy to enhance the high energy density of EDLCs. For a 2-electrode assembly of EDLC in Fig. 9a, the stored charges on anode and cathode are balanced, $\mathrm{i}$. e., $Q_{+}=C_{+} V_{+}=Q_{-}=C_{-} V_{-}$. Given $C_{+} \neq C_{-}$, due to the different chemical nature of anions and cations in the formation of EDLs, a high operating potential may exceed the stability limit of electrolytes, which would lead to the decomposition of electrolytes and affect the stability of EDLCs in the whole cell voltage. Thus, the cell voltage $(V)$ may be limited by the electrode with either lower $C_{+}$or $C_{\text {. }}$. As described in Fig. 9b, the asymmetric shapes of cyclic voltammograms for different electrochemical stability of cations and anions, are also reflected by the asymmetric $C_{\mathrm{d}}$ in Figs 5 and 6 . One strategy to enhance the balance of capacitive performance is to adjust the mass ratio between anode and cathode by $\frac{m_{+}}{m_{-}}=\frac{C_{-} V_{-, \max }}{C_{+} V_{+, \max }}$ $[88,89,99]$, in which $m_{+}$and $m_{-}$are the masses of anode and cathode, respectively, and $C_{+}$and $C_{-}$are the corresponding capacitance; $V_{+, \max }$ and $V_{-, \max }$ denote the max- 
imum operating potential vs. PZC. However, such strategy can limit the gravimetric specific capacitance.

Recently, formulating IL/IL binary electrolytes was proposed to achieve balance capacitance between $C_{+}$and $C_{-}$to increase the cell voltage and thus to enhance the energy density. The main mechanism in IL/IL mixtures is to modify the selectivity of ion adsorption by ionic electrostatic interactions and ionic steric effects (sieving effects) $[100,101]$. Thus, the oscillating layering structure can be optimized by increasing the overall ionic packing density and therefore decreasing the effective thickness of EDLs. In IL/IL mixed electrolytes composed by $\left[\mathrm{C}_{2} \mathrm{MIm}\right] \mathrm{BF}_{4}$ and $\left[\mathrm{N}_{111}\right] \mathrm{BF}_{4}$, the weaker interactions in $\left[\mathrm{C}_{2} \mathrm{MIm}\right]^{+}-\mathrm{BF}_{4}^{-}$may facilitate ions to enter micropores, while the cation-cation interactions between $\left[\mathrm{C}_{2} \mathrm{MIm}\right]^{+}$ and $\left[\mathrm{N}_{1111}\right]$ may result in an increased packing population [100]. Van Aken et al. [102] altered the IL/IL mixed ratio of $\left[\mathrm{C}_{2} \mathrm{MIm}\right] \mathrm{TFSI}$ and $\left[\mathrm{C}_{2} \mathrm{MIm}\right] \mathrm{BF}_{4}$, and the mixtures with $20 \mathrm{vol} \%\left[\mathrm{C}_{2} \mathrm{MIm}\right] \mathrm{BF}_{4}$ showed the balanced potential distribution between negative and positive electrode (in Fig. 9c). In further GCD tests, $\left[\mathrm{C}_{2} \mathrm{MIm}\right] \mathrm{TFSI}$ exhibited only $20 \%$ retention of initial capacitance with a large decay after $\sim 4000$ cycles, while the mixture with 20 vol\% $\left[\mathrm{C}_{2} \mathrm{MIm}\right] \mathrm{BF}_{4}$ performed the best retention of up to $95 \%$ of its initial capacitance (in Fig. 9d). The reason is that the cell voltage of $3.5 \mathrm{~V}$ exceeds the maximum electrochemical window for neat $\left[\mathrm{C}_{2} \mathrm{MIm}\right] \mathrm{TFSI}$, while the addition of $20 \mathrm{vol} \%\left[\mathrm{C}_{2} \mathrm{MIm}\right] \mathrm{BF}_{4}$ enhances the capacitance $\mathrm{C}_{+}$contributed by anions. The enhanced capacitance originates from ionic steric volume, which balances the electrochemical window between anode and cathode. Thus, optimizing the ratio of IL composition can balance capacitance between anode and cathode, which can enhance the cell voltage and thus increase the energy storage capability of symmetric EDLCs. On the other hand, the utilization of the entire operating potential range is not only dominated by the balanced electrochemical window of anode and cathode, but also governed by the ratio of $V_{-}$ $/ V_{+}$related to $C_{+} / C_{-}$.

Table S2 summarizes the dependence of the gravimetric specific capacitance and energy density on the compositions of IL electrolytes including pure ILs, IL/IL binary electrolytes, IL/organic solvent mixtures, as well as functionalized ILs. Understanding of experimental results in Table S2 confirms that selective of ion adsorption in the pore plays an important role in determining the electrochemical performance of EDLCs, owing to the formation of EDLs. The volumetric limitation would dominate ionic population in the pore and ionic orientation, and thus dominate the accessible surface areas, which may affect the ionic packing density and further the thickness of EDLs. In Table S2, $\left[\mathrm{C}_{2} \mathrm{MIm}\right] \mathrm{BF}_{4}$ exhibits a high energy density of $46 \mathrm{~W} \mathrm{~h} \mathrm{~kg}^{-1}$ with laser-scribed graphene electrode, due to its relatively high gravimetric specific capacitance of $276 \mathrm{~F} \mathrm{~g}^{-1}$ and relatively high cell voltage of $4 \mathrm{~V}$ [85]. Ionic electrostatic interactions can also drive selective ions to enter pores for high ionic density packing. The ether-functionalized IL of $\left[\mathrm{Pyr}_{1,1 \mathrm{O} 1}\right] \mathrm{FSI}$, displays a high gravimetric specific capacitance of $206 \mathrm{~F} \mathrm{~g}^{-1}$, partially attributed to the incorporation of ether group which provides larger accessibility of ions into the pores of the electrode surface [90]. It is notable that low cell voltage of $2.5 \mathrm{~V}$ for $\left[\mathrm{Pyr}_{1,3}\right]$ FSI with a gravimetric specific capacitance of $181 \mathrm{Fg}^{-1}$, limits its energy density of $11.8 \mathrm{~W} \mathrm{~h} \mathrm{~kg}^{-1}$ [90], which is in contrast to the wide electrochemical window of ammonium-based ILs reported in Table S1, especially $5.7 \mathrm{~V}$ for $\left[\mathrm{N}_{1114}\right] \mathrm{TFSI}$ electrolyte [16]. Thus, a balance capacitance between $C_{+}$ and $C_{-}$is essential to improve the cell voltage of ammonium-based ILs that own wider electrochemical window than the imidazolium-based ILs, further enhancing the energy density. It is also notable that IL/organic solvent mixed electrolytes do not significantly provide higher gravimetric specific capacitance compared with the pure ILs, though they exhibit higher $C_{\mathrm{d}}$ in Table S1. This apparent contradiction may be understood by noticing that $C_{\mathrm{d}}$ in Table S1 was measured with flat electrodes, while the gravimetric specific capacitances were conducted with porous electrodes. Thus, the solvation of ions in IL/organic mixed electrolytes cannot be neglected if the volumetric limitation of solvation increases the electrostatic screening length. Meanwhile, if pores were filled with organic solvents, the screening of the free charges on the electrode surface would not be as efficient as counterions.

On the other hand, most of the $C_{\mathrm{SSA}}$ in Table S2 is lower than the $C_{\mathrm{d}}$ in Table $\mathrm{S} 1$, which means that the effective SSA may not be fully utilized, and further confirms the selection of ions in pores is essential to achieve the maximal utilization of SSA with optimizing PSD. Zhang et al. [103] proposed estimating effective SSA (ESSA) for the accessible area via the cumulative area of the pores with size above the diameter of cations of ILs, which was generally larger than that of anions. Specifically, for $\left[\mathrm{C}_{2} \mathrm{MIm}\right]^{+}$with a diameter of $0.75 \mathrm{~nm}$, the ESSA is $1657 \mathrm{~m}^{2} \mathrm{~g}^{-1}$, which is about $93 \%$ of the SSA of $1779 \mathrm{~m}^{2} \mathrm{~g}^{-1}$. Thus, the $C_{\mathrm{SSA}}$ is $13.3 \mu \mathrm{F} \mathrm{cm} \mathrm{cm}^{-2}$ using ESSA instead of $12.4 \mu \mathrm{F} \mathrm{cm}^{-2}$ using SSA, estimated via the gravimetric specific capacitance of $220 \mathrm{~F} \mathrm{~g}^{-1}$. This report provides a nice attempt to estimate the upper limit of 
ESSA. The highest $C_{\text {SSA }}$ from Table S2 is $24.9 \mu \mathrm{F} \mathrm{cm}^{-2}$, using a small size $\mathrm{IL},\left[\mathrm{C}_{2} \mathrm{MIm}\right] \mathrm{BF}_{4}$, with graphene sheet electrodes with dominant average pore size about $3.6 \mathrm{~nm}$ [83]. Thus, such high $C_{\text {SSA }}$ may be understood as $100 \%$ usage of SSA of $481.5 \mathrm{~m}^{2} \mathrm{~g}^{-1}$, with additional gain via the nano-confined ions [70]. Unfortunately, the relatively smaller SSA gives a gravimetric specific capacitance of $120 \mathrm{~F} \mathrm{~g}^{-1}$. Therefore, a large ESSA is essential to high gravimetric specific capacitance as well as the appropriate PSD, owing to the large area accessibility and the favorability of the ionic orientation in the pores.

At this point, it is of interest to estimate the upper limit of EDLCs. It was reported the quantum limit of a perfect graphene $C_{\mathrm{SSA}}$ is $21 \mu \mathrm{F} \mathrm{cm}^{-2}$ [104]. Considering the theoretical SSA of perfect graphene of $A=2630 \mathrm{~m}^{2} \mathrm{~g}^{-1}$ $[87,105]$, the theoretical gravimetric specific capacitance of graphene is $\sim 550 \mathrm{~F} \mathrm{~g}^{-1}$ [85]. In addition, if SSA of $2630 \mathrm{~m}^{2} \mathrm{~g}^{-1}$ is available by $80 \%$ for charging/discharging process, the above theoretical capacitance can decay to $\sim 440 \mathrm{~F} \mathrm{~g}^{-1}$ [106]. Assuming further that the electrode materials take $30 \%$ of the total weight of a symmetric EDLC with a cell voltage of $4.0 \mathrm{~V}$, the energy density of such assembled EDLC would be $73 \mathrm{~W} \mathrm{~h} \mathrm{~kg}^{-1}$. Would this be the upper limit of EDLC? Not necessary! Based on the above studies, (1) the introduction of ILs as electrolytes can greatly enhance the electrochemical window up to $5 \mathrm{~V}$; (2) the recently reported defective graphene has larger SSA up to $3523 \mathrm{~m}^{2} \mathrm{~g}^{-1}$ [79]; (3) nano-confined IL pore can deliver high capacitance [70]. Thus, there is still much room to improve the energy density of IL-based EDLCs.

\section{IL GEL POLYMER ELECTROLYTE INSTEAD OF LIQUID ELECTROLYTE APPLIED IN EDLC}

Considering the electrolyte leakage problem, IL gel polymer electrolytes (IL-GPEs) are applied in solid-state EDLCs instead of liquid electrolytes. Normally, IL-GPEs possess high ionic conductivity and flexibility as well as wide operating voltage and nonflammability, almost comparable to liquid electrolytes [107]. These advantages help to develop flexible structures and tunable shapes for various applications [2]. Generally, GPEs essentially consist of host polymer matrix, transport electrolyte ions and plasticizers [108]. In IL-GPEs, ILs are assumed as both transport electrolyte ions and plasticizers. A schematic illustration of IL-GPEs as a media to transport ions and separator between two electrodes in a solid-state EDLC is described in Fig. 10a. The charging and discharging mechanisms in EDLCs confirm the fact that

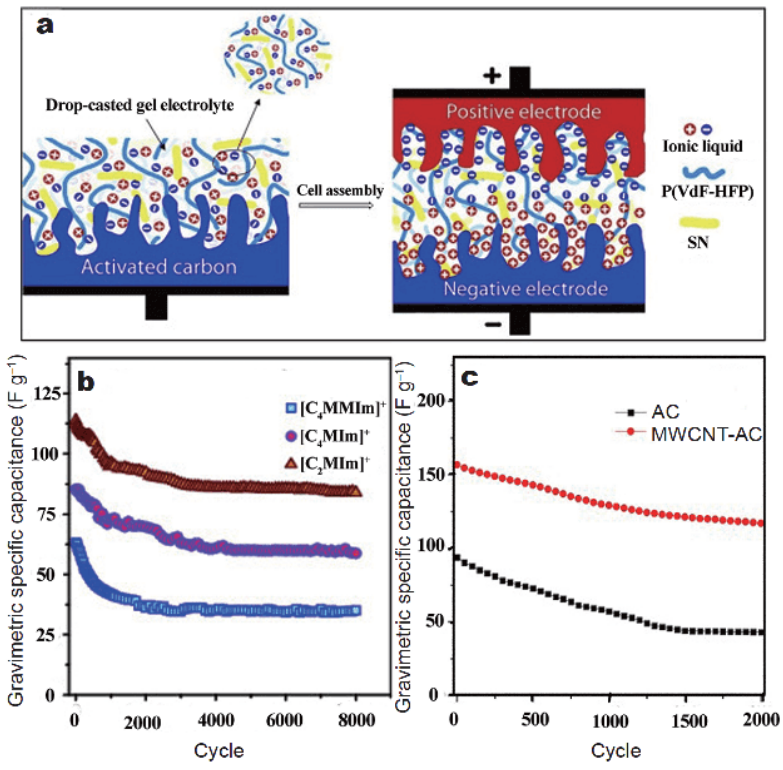

Figure 10 (a) Scheme of solid-state EDLC with IL-GPEs. Reprinted with permission from Ref. [116]. Copyright 2016, Elsevier. (b) The cyclic stability of IL-GPEs with increased cationic size at a current density of $1.0 \mathrm{~mA} \mathrm{~cm}^{-2}$. Reprinted with permission from Ref. [108]. Copyright 2018, Elsevier. (c) Cycling performance of $\left[\mathrm{Pyr}_{1,3}\right]$ TFSI-GPEs on AC electrode and MWCNT added AC electrode. Reprinted with permission from Ref. [111]. Copyright 2018, Elsevier.

charge storage predominantly involves surface diffusion $(<10 \mathrm{~nm})$, and is not controlled by bulk diffusion of ions across the cell $[46,109]$. However, it should be noted that the limited contact surface area between IL-GPEs and electrode materials, could increase the internal resistance and limit the utilized SSA of electrodes [2]. To date, various polymer matrices have been used in solid-state EDLCs, including poly(vinylidene fluoride) (PVdF), poly (hexafluoropylene) (PHFP), poly(vinylidene fluoride-cohexafluoropylene) (P(VdF-HFP)), poly(methyl methacrylate-co-dopamine methacrylate) (P(MMA-DMA)), and etc. [110]. Among them, P(VdF-HFP) copolymer is mostly utilized to prepare IL-GPEs owing to the semicrystalline structure containing both crystalline and amorphous behaviors [111], while standard solution cast technique is frequently used in preparation of IL-GELs $[112,113]$.

As reported, a solid-state EDLC with IL-GPEs can achieve higher capacitive performance than that using liquid electrolytes [114,115]. Pandey et al. [116] found that with the incorporation of $\left[\mathrm{C}_{4} \mathrm{MIm}\right] \mathrm{BF}_{4}$-GPEs, the solid-state EDLCs showed a specific capacitance of $110 \mathrm{~F} \mathrm{~g}^{-1}$, which was higher than $77 \mathrm{~F} \mathrm{~g}^{-1}$ for that with $\left[\mathrm{C}_{4} \mathrm{MIm}\right] \mathrm{BF}_{4}$-liquid electrolytes. Interestingly, the properties of ILs and the SSA of electrode materials also play 
an important role in the performance of solid-state EDLCs. In Fig. 10b, a comparison of capacitive performance of IL-GPEs with different cationic sizes demonstrates that the gravimetric specific capacitance increases with the decreased cationic size, where a high specific capacitance of $113.6 \mathrm{~F} \mathrm{~g}^{-1}$ is obtained at $1.0 \mathrm{~mA} \mathrm{~cm}{ }^{-2}$ with smaller size of $\left[\mathrm{C}_{2} \mathrm{MIm}\right]^{+}$[108]. As described in Fig. 10c, the electrode properties influence the cyclic stability of $\left[\right.$ Pyr $\left._{1,3}\right]$ TFSI-GPEs-based solid-state EDLCs, where a higher specific capacity retention of $75 \%$ is obtained by multi-wall carbon nanotube (MWCNT) added AC (MWCNT-AC) electrode compared with $48 \%$ for the AC electrode [111]. The results are very consistent with the capacitive performance in EDLCs with liquid electrolytes, where volumetric limitation of ions dominates the formation of EDLs. Therefore, fundamental understanding of liquid electrolytes in EDLCs is helpful to prepare ILGPEs incorporated with electrodes, which can also benefit IL-GPEs as promising candidates for the development of solid-state EDLCs.

Recently, some efforts were devoted to achieving high performance of solid-state EDLCs. Zhang et al. [117] prepared the supported IL-gel membrane electrolytes (ILGMEs) by incorporating IL-gel into commercial porous supports. They found that the solid-state EDLCs with $\left[\mathrm{C}_{2} \mathrm{MIm}\right]$ TFSI-GMEs exhibited a high gravimetric specific capacitance of $153 \mathrm{~F} \mathrm{~g}^{-1}$ and excellent cycle stability, with as high as $97 \%$ of the original capacitance after 10,000 charging/discharging cycles. Yang et al. [114] reported that the addition of conductive graphene oxide (GO) could significantly improve the conductivity of ILGPEs. The solid-state EDLCs with GO-doped $\left[\mathrm{C}_{2} \mathrm{MIm}\right] \mathrm{BF}_{4}$-GPEs exhibit better cycle stability and a high specific energy density of $9.7 \mathrm{~W} \mathrm{~h} \mathrm{~kg}^{-1}$. Jin et al. [118] prepared a high-performance boron-containing GPE with semi-interpenetrating polymer network structure incorporating with the anion-trapping boron sites, which was beneficial to a better capacitance retention of $91.2 \%$. One of the recent host polymers is the poly(ionic liquid) (PIL) by polymerizing the IL itself [119-121]. de Oliveira et al. [122] investigated the influence of the synthesized PIL/IL-GPEs on the properties of solid-state EDLCs. They found that the solid-state EDLCs with binary blend of poly(diallydimethylammonium) bis(trifluoromethan- esulfonyl)imide (PILTFSI) and $\left[\mathrm{C}_{3}\right.$ MMIm]TFSI-GPEs maintained $93 \%$ of capacitance after 1000 cycles, which was remarkably higher than that of solid-state EDLCs with $\left[\mathrm{C}_{4} \mathrm{MIm}\right] \mathrm{FSI}-\mathrm{GPEs}$. The results demonstrate that the match of the properties of ILs with the PIL's is important in the charge storage of solid-state
EDLCs.

\section{SUMMARY}

EDLCs store free charges on the electrode surface via non-Faradaic process, which is balanced by the EDL formed by the counter-ions in the electrolytes. Thus, EDLCs exhibit high cycle stability and excellent power density. Owing to their environmental benignity and wide electrochemical windows (up to $5 \mathrm{~V}$ ), ILs are considered as promising electrolytes in EDLCs with high energy density. In this review, we focus on the ILs that are potentially capable of fulfilling such goal, and also focus on both the $C_{\mathrm{d}}$ with flat electrode to explore the EDL structures with small effective EDL thickness, as well as the gravimetric specific capacitance with porous carbon materials electrode with high SSA and appropriate PSD. The chemical composition of ILs, ionic sizes, ionic structures and ionic interactions play key roles in the formation of EDL, along with the SSA and PSD of electrode materials.

Imidazolium- and ammonium-based ILs are the most widely investigated electrolytes in EDLCs. The experimental results demonstrate that the volumetric limitation dominates the ionic packing density in the pore, owing to the sieving effect and ionic orientation, which may be also governed by the ionic interactions and interactions between ions and electrodes. For pure ILs, $\left[\mathrm{C}_{2} \mathrm{MIm}\right] \mathrm{BF}_{4}$ can exhibit a high gravimetric specific capacitance of $276 \mathrm{~F} \mathrm{~g}^{-1}$ [85], while $\left[\mathrm{Pyr}_{1,3}\right]$ FSI displays a gravimetric specific capacitance of $181 \mathrm{~F} \mathrm{~g}^{-1}$ [90]. Thus, a high energy density can be up to $46 \mathrm{~W} \mathrm{~h} \mathrm{~kg}^{-1}$ for $\left[\mathrm{C}_{2} \mathrm{MIm} \mathrm{BF}_{4}\right.$ with a cell voltage of $4 \mathrm{~V}$ [85]. The charging EDLs formed on the electrode surface with oscillation layering and overscreening originated form strong ionic interactions of ILs, would limit the capacitive performance of EDLCs. Considering such overscreening effect in EDLs, ILs diluted with organic solvents and functionalized by organic group are proposed as efficient strategies. When organic solvents disperse ions, $1.0 \mathrm{~mol} \mathrm{~L}^{-1}\left[\mathrm{~N}_{2222}\right] \mathrm{BF}_{4} / \mathrm{AN}$ mixture achieves $202 \mathrm{~F} \mathrm{~g}^{-1}$ for gravimetric specific capacitance [79]. It is also notable that IL/organic solvent mixtures, though generally have higher capacitance than the pure ILs, do not deliver higher energy density in EDLCs compared with the pure ones. The reason may be attributed to the pores filled with the organic solvent, which results in inefficient screening of the electrode charge as well as the narrow electrochemical window of the organic solvent. Functionalized IL with electronegative group on the cations, such as $\left[\mathrm{Pyr}_{1,1 \mathrm{O} 1}\right]$ FSI with ether-substitutent exhibits a higher gravimetric specific capacitance of 
$206 \mathrm{~F} \mathrm{~g}^{-1}$ than that of $181 \mathrm{~F} \mathrm{~g}^{-1}$ for [ $\mathrm{Pyr}_{1,3}$ ]FSI [90]. It is notable that the influence of the solvation of ions on the formation of EDLs and the organic group/organic solvents on the electrochemical window cannot be neglected.

On the other hand, a high energy density can be up to $46 \mathrm{~W} \mathrm{~h} \mathrm{~kg}^{-1}$ for $\left[\mathrm{C}_{2} \mathrm{MIm}\right] \mathrm{BF}_{4}$ with a cell voltage of $4 \mathrm{~V}$ [85]. Generally, the ammonium-based ILs have wider electrochemical window compared with imidazoliumbased ILs according to the measurements in three electrode system. However, the entire electrochemical window of most ILs may not be fully utilized in two-electrode EDLCs, due to unbalance of capacitance between anode and cathode, which results in limitation of cell voltage by the decomposition of electrolyte ions. The balance of capacitance between cathode and anode is essential to impose high cell voltage for ammonium-based ILs, which can further optimize the cycle stability and energy density.

Based on the current studies of IL electrolytes in EDLCs, it can be found that the smaller ions can penetrate into pores and thus may contribute to higher energy density than bulky ions. On the other hand, the strong ionic correlation correlated with small ions, and ion pairs do not contribute to the EDL capacitance, or their contributions are limited if considered as dielectrics. This results in the insufficient screening of the electrode potential, further depresses the capacitive performance and affects the specific energy. In order to overcome the drawback of neat ILs, functionalized ILs with electronegative group on the cations may inherent the higher capacitance as IL/organic solvent mixtures, while keeping a wide electrochemical window. The cell voltage of EDLCs may be optimized with IL/IL mixtures. Additionally, fundamental understanding of capacitive performance in liquid electrolytes of ILs is useful to design "designer transport ions" and to prepare electrodes incorporated with IL-GPEs, which can also benefit IL-GPEs as promising candidates for the development of solidstate EDLCs. Based on the above consideration, it is worthy to further explore the ammonium-based ILs with wide electrochemical window, mixing with functionalized ILs to increase capacitance with balanced cell voltage, in the practical applications of EDLCs toward higher energy density.

Received 13 May 2019; accepted 13 June 2019;

published online 24 July 2019

1 Liu W, Yan X, Lang J, et al. Electrochemical behavior of graphene nanosheets in alkylimidazolium tetrafluoroborate ionic liquid electrolytes: Influences of organic solvents and the alkyl chains. J
Mater Chem, 2011, 21: 13205-13212

2 Zhong C, Deng Y, Hu W, et al. A review of electrolyte materials and compositions for electrochemical supercapacitors. Chem Soc Rev, 2015, 44: 7484-7539

3 Smith GD, Borodin O, Li L, et al. A comparison of ether- and alkyl-derivatized imidazolium-based room-temperature ionic liquids: A molecular dynamics simulation study. Phys Chem Chem Phys, 2008, 10: 6301-6312

4 Salanne M, Rotenberg B, Naoi K, et al. Efficient storage mechanisms for building better supercapacitors. Nat Energy, 2016, 1: 16070

5 Tang J, Wang J, Shrestha LK, et al. Activated porous carbon spheres with customized mesopores through assembly of diblock copolymers for electrochemical capacitor. ACS Appl Mater Interfaces, 2017, 9: 18986-18993

6 Balducci A. Electrolytes for high voltage electrochemical double layer capacitors: A perspective article. J Power Sources, 2016, 326: 534-540

7 Pohlmann S, Olyschläger T, Goodrich P, et al. Azepanium-based ionic liquids as green electrolytes for high voltage supercapacitors. J Power Sources, 2015, 273: 931-936

8 Pohlmann S, Olyschläger T, Goodrich $\mathrm{P}$, et al. Mixtures of azepanium based ionic liquids and propylene carbonate as high voltage electrolytes for supercapacitors. Electrochim Acta, 2015, 153: 426-432

9 Abbas Q, Béguin F. High voltage AC/AC electrochemical capacitor operating at low temperature in salt aqueous electrolyte. J Power Sources, 2016, 318: 235-241

10 Bhise SC, Awale DV, Vadiyar MM, et al. Facile synthesis of $\mathrm{CuO}$ nanosheets as electrode for supercapacitor with long cyclic stability in novel methyl imidazole-based ionic liquid electrolyte. J Solid State Electrochem, 2017, 21: 2585-2591

11 Abbas Q, Babuchowska P, Frąckowiak E, et al. Sustainable AC/ AC hybrid electrochemical capacitors in aqueous electrolyte approaching the performance of organic systems. J Power Sources, 2016, 326: 652-659

12 Frackowiak E, Béguin F. Carbon materials for the electrochemical storage of energy in capacitors. Carbon, 2001, 39: 937-950

13 Fic K, Meller M, Menzel J, et al. Around the thermodynamic limitations of supercapacitors operating in aqueous electrolytes. Electrochim Acta, 2016, 206: 496-503

14 Li G, Gao X, Wang K, et al. Porous carbon nanospheres with high EDLC capacitance. Diamond Related Mater, 2018, 88: 12-17

15 Leyva-García S, Lozano-Castelló D, Morallón E, et al. Electrochemical performance of a superporous activated carbon in ionic liquid-based electrolytes. J Power Sources, 2016, 336: 419-426

16 Klein JM, Panichi E, Gurkan B. Potential dependent capacitance of [EMIM][TFSI], [N $\mathrm{N}_{1114}$ ] [TFSI] and [PYR ${ }_{13}$ ][TFSI] ionic liquids on glassy carbon. Phys Chem Chem Phys, 2019, 21: 3712-3720

17 Lei Z, Liu Z, Wang H, et al. A high-energy-density supercapacitor with graphene-CMK-5 as the electrode and ionic liquid as the electrolyte. J Mater Chem A, 2013, 1: 2313-2321

18 Helmholtz H. Ueber einige Gesetze der Vertheilung elektrischer Ströme in körperlichen Leitern, mit Anwendung auf die thierisch-elektrischen Versuche (Schluss.). Ann Phys Chem, 1853, 165: 353-377

19 Vu A, Li X, Phillips J, et al. Three-dimensionally ordered mesoporous (3DOm) carbon materials as electrodes for electrochemical double-layer capacitors with ionic liquid electrolytes. Chem Mater, 2013, 25: 4137-4148 
20 Chang P, Wang C, Kinumoto T, et al. Frame-filling C/C composite for high-performance EDLCs with high withstanding voltage. Carbon, 2018, 131: 184-192

21 Zhao J, Jiang Y, Fan H, et al. Porous 3D few-layer graphene-like carbon for ultrahigh-power supercapacitors with well-defined structure-performance relationship. Adv Mater, 2017, 29: 1604569

22 Heckmann A, Fromm O, Rodehorst U, et al. New insights into electrochemical anion intercalation into carbonaceous materials for dual-ion batteries: Impact of the graphitization degree. Carbon, 2018, 131: 201-212

23 Chang P, Matsumura K, Wang C, et al. Frame-filling structural nanoporous carbon from amphiphilic carbonaceous mixture comprising graphite oxide. Carbon, 2016, 108: 225-233

24 Moreno-Fernández G, Schütter C, Rojo JM, et al. On the interaction of carbon electrodes and non conventional electrolytes in high-voltage electrochemical capacitors. J Solid State Electrochem, 2018, 22: 717-725

25 Zhan C, Lian C, Zhang Y, et al. Computational insights into materials and interfaces for capacitive energy storage. Adv Sci, 2017, 4: 1700059

26 Terasawa N. High-performance transparent actuator made from poly(dimethylsiloxane)/ionic liquid gel. Sensor Actuat B-Chem, 2018, 257: 815-819

27 Tooming $\mathrm{T}$, Thomberg $\mathrm{T}$, Kurig $\mathrm{H}$, et al. High power density supercapacitors based on the carbon dioxide activated d-glucose derived carbon electrodes and 1-ethyl-3-methylimidazolium tetrafluoroborate ionic liquid. J Power Sources, 2015, 280: 667-677

28 Zhai Y, Dou Y, Zhao D, et al. Carbon materials for chemical capacitive energy storage. Adv Mater, 2011, 23: 4828-4850

29 Béguin F, Presser V, Balducci A, et al. Carbons and electrolytes for advanced supercapacitors. Adv Mater, 2014, 26: 2219-2251

30 Dyatkin B, Osti NC, Zhang Y, et al. Ionic liquid structure, dynamics, and electrosorption in carbon electrodes with bimodal pores and heterogeneous surfaces. Carbon, 2018, 129: 104-118

31 Jeon H, Han JH, Yu DM, et al. Synthesis of mesoporous reduced graphene oxide by $\mathrm{Zn}$ particles for electrodes of supercapacitor in ionic liquid electrolyte. J Indust Eng Chem, 2017, 45: 105-110

32 Kerisit S, Schwenzer B, Vijayakumar M. Effects of oxygen-containing functional groups on supercapacitor performance. J Phys Chem Lett, 2014, 5: 2330-2334

33 Phattharasupakun N, Wutthiprom J, Suktha P, et al. High-performance supercapacitors of carboxylate-modified hollow carbon nanospheres coated on flexible carbon fibre paper: Effects of oxygen-containing group contents, electrolytes and operating temperature. Electrochim Acta, 2017, 238: 64-73

34 Jiang L, Sheng L, Fan Z. Biomass-derived carbon materials with structural diversities and their applications in energy storage. Sci China Mater, 2018, 61: 133-158

35 Wang DW, Li F, Liu M, et al. 3D aperiodic hierarchical porous graphitic carbon material for high-rate electrochemical capacitive energy storage. Angew Chem Int Ed, 2008, 47: 373-376

36 Wang X, Zhou H, Sheridan E, et al. Geometrically confined favourable ion packing for high gravimetric capacitance in carbonionic liquid supercapacitors. Energy Environ Sci, 2016, 9: 232239

37 Chapman DL. LI. A contribution to the theory of electrocapillarity. London Edinburgh Dublin Philos Mag J Sci, 1913, 25: 475-481

38 Gouy M. Sur la constitution de la charge électrique à la surface d'un électrolyte. J de Phys, 1910, 9: 457-468

39 Gebbie MA, Smith AM, Dobbs HA, et al. Long range electrostatic forces in ionic liquids. Chem Commun, 2017, 53: 1214-1224

40 Lee AA, Perez-Martinez CS, Smith AM, et al. Underscreening in concentrated electrolytes. Faraday Discuss, 2017, 199: 239-259

41 Smith AM, Lee AA, Perkin S. The electrostatic screening length in concentrated electrolytes increases with concentration. J Phys Chem Lett, 2016, 7: 2157-2163

42 Feng G, Huang J, Sumpter BG, et al. A "counter-charge layer in generalized solvents" framework for electrical double layers in neat and hybrid ionic liquid electrolytes. Phys Chem Chem Phys, 2011, 13: 14723-14734

43 Lucio AJ, Shaw SK. Capacitive hysteresis at the 1-ethyl-3-methylimidazolium tris(pentafluoroethyl)-trifluorophosphate-polycrystalline gold interface. Anal Bioanal Chem, 2018, 410: 45754586

44 Zhan C, Zhang Y, Cummings PT, et al. Computational insight into the capacitive performance of graphene edge planes. Carbon, 2017, 116: 278-285

45 Wippermann K, Giffin J, Kuhri S, et al. The influence of water content in a proton-conducting ionic liquid on the double layer properties of the Pt/PIL interface. Phys Chem Chem Phys, 2017, 19: $24706-24723$

46 Eftekhari A. The mechanism of ultrafast supercapacitors. J Mater Chem A, 2018, 6: 2866-2876

47 Drüschler M, Borisenko N, Wallauer J, et al. New insights into the interface between a single-crystalline metal electrode and an extremely pure ionic liquid: Slow interfacial processes and the influence of temperature on interfacial dynamics. Phys Chem Chem Phys, 2012, 14: 5090-5099

48 Drüschler M, Huber B, Roling B. On capacitive processes at the interface between 1-ethyl-3-methylimidazolium tris(pentafluoroethyl)trifluorophosphate and $\mathrm{Au}(111)$. J Phys Chem C, 2011, 115: 6802-6808

49 Zhang Q, Liu X, Yin L, et al. Electrochemical impedance spectroscopy on the capacitance of ionic liquid-acetonitrile electrolytes. Electrochim Acta, 2018, 270: 352-362

50 Roling B, Drüschler M, Huber B. Slow and fast capacitive process taking place at the ionic liquid/electrode interface. Faraday Discuss, 2012, 154: 303-311

51 Atkin R, Borisenko N, Drüschler M, et al. An in situ STM/AFM and impedance spectroscopy study of the extremely pure 1-butyl1-methylpyrrolidinium tris(pentafluoroethyl)trifluorophosphate/ $\mathrm{Au}(111)$ interface: Potential dependent solvation layers and the herringbone reconstruction. Phys Chem Chem Phys, 2011, 13: 6849-6857

52 Vargas-Barbosa NM, Roling B. Time-resolved determination of the potential of zero charge at polycrystalline Au/ionic liquid interfaces. J Chem Phys, 2018, 148: 193820

53 Su YZ, Fu YC, Yan JW, et al. Double layer of $\mathrm{Au}(100) /$ ionic liquid interface and its stability in imidazolium-based ionic liquids. Angew Chem Int Ed, 2009, 48: 5148-5151

$54 \mathrm{Hu} \mathrm{X}$, Chen C, Yan J, et al. Electrochemical and in-situ scanning tunneling microscopy studies of bis(fluorosulfonyl)imide and bis (trifluoromethanesulfonyl)imide based ionic liquids on graphite and gold electrodes and lithium salt influence. J Power Sources, 2015, 293: 187-195

55 Anderson E, Grozovski V, Siinor L, et al. Influence of the electrode potential and in situ STM scanning conditions on the phase boundary structure of the single crystal $\mathrm{Bi}(111) \mid 1$-butyl-4-methyl- 
pyridinium tetrafluoroborate interface. J Electroanal Chem, 2013, 709: 46-56

56 Pajkossy T, Kolb DM. The interfacial capacitance of $\mathrm{Au}(100)$ in an ionic liquid, 1-butyl-3-methyl-imidazolium hexafluorophosphate. Electrochem Commun, 2011, 13: 284-286

57 Li MG, Chen L, Zhong YX, et al. The electrochemical interface of $\mathrm{Ag}(111)$ in 1-ethyl-3-methylimidazolium bis(trifluoromethylsulfonyl)imide ionic liquid-A combined in-situ scanning probe microscopy and impedance study. Electrochim Acta, 2016, 197: 282-289

58 Wallauer J, Drüschler M, Huber B, et al. The differential capacitance of ionic liquid/metal electrode interfaces-A critical comparison of experimental results with theoretical predictions. Z für Naturforschung B, 2013, 68: 1143-1153

59 Kornyshev AA. Double-layer in ionic liquids: paradigm change? J Phys Chem B, 2007, 111: 5545-5557

60 Fedorov MV, Kornyshev AA. Ionic liquids at electrified interfaces. Chem Rev, 2014, 114: 2978-3036

61 Islam MM, Alam MT, Okajima T, et al. Electrical double layer structure in ionic liquids: An understanding of the unusual capacitance-potential curve at a nonmetallic electrode. J Phys Chem C, 2009, 113: 3386-3389

62 Bozym DJ, Uralcan B, Limmer DT, et al. Anomalous capacitance maximum of the glassy carbon-ionic liquid interface through dilution with organic solvents. J Phys Chem Lett, 2015, 6: 26442648

63 Goodwin ZAH, Feng G, Kornyshev AA. Mean-field theory of electrical double layer in ionic liquids with account of short-range correlations. Electrochim Acta, 2017, 225: 190-197

64 Lockett V, Horne M, Sedev R, et al. Differential capacitance of the double layer at the electrode/ionic liquids interface. Phys Chem Chem Phys, 2010, 12: 12499-12512

65 Eftekhari A. On the mechanism of microporous carbon supercapacitors. Mater Today Chem, 2018, 7: 1-4

66 Forse AC, Merlet C, Griffin JM, et al. New perspectives on the charging mechanisms of supercapacitors. J Am Chem Soc, 2016, 138: $5731-5744$

67 Wu P, Huang J, Meunier V, et al. Voltage dependent charge storage modes and capacity in subnanometer pores. J Phys Chem Lett, 2012, 3: 1732-1737

68 Huang Y, Liang J, Chen Y. An overview of the applications of graphene-based materials in supercapacitors. Small, 2012, 8: 1805-1834

69 Rennie AJR, Martins VL, Smith RM, et al. Influence of particle size distribution on the performance of ionic liquid-based electrochemical double layer capacitors. Sci Rep, 2016, 6: 22062

70 Chmiola J, Yushin G, Gogotsi Y, et al. Anomalous increase in carbon capacitance at pore sizes less than 1 nanometer. Science, 2006, 313: 1760-1763

71 Huang J, Sumpter BG, Meunier V. Theoretical model for nanoporous carbon supercapacitors. Angew Chem Int Ed, 2008, 47: 520-524

72 Feng G, Cummings PT. Supercapacitor capacitance exhibits oscillatory behavior as a function of nanopore size. J Phys Chem Lett, 2011, 2: 2859-2864

73 Huang J, Sumpter BG, Meunier V, et al. Curvature effects in carbon nanomaterials: Exohedral versus endohedral supercapacitors. J Mater Res, 2011, 25: 1525-1531

74 Feng G, Qiao R, Huang J, et al. The importance of ion size and electrode curvature on electrical double layers in ionic liquids.
Phys Chem Chem Phys, 2011, 13: 1152-1161

75 Feng G, Jiang DE, Cummings PT. Curvature effect on the capacitance of electric double layers at ionic liquid/onion-like carbon interfaces. J Chem Theor Comput, 2012, 8: 1058-1063

76 Noh C, Jung YJ. Understanding the charging dynamics of an ionic liquid electric double layer capacitor via molecular dynamics simulations. Phys Chem Chem Phys, 2019, 21: 6790-6800

77 Liu X, Wang Y, Li S, et al. Effects of anion on the electric double layer of imidazolium-based ionic liquids on graphite electrode by molecular dynamics simulation. Electrochim Acta, 2015, 184: 164-170

78 Jo S, Park SW, Noh C, et al. Computer simulation study of differential capacitance and charging mechanism in graphene supercapacitors: Effects of cyano-group in ionic liquids. Electrochim Acta, 2018, 284: 577-586

79 Zhang L, Zhang F, Yang X, et al. Porous 3D graphene-based bulk materials with exceptional high surface area and excellent conductivity for supercapacitors. Sci Rep, 2013, 3: 1408

80 DeRosa D, Higashiya S, Schulz A, et al. High performance spiro ammonium electrolyte for electric double layer capacitors. J Power Sources, 2017, 360: 41-47

81 Nguyen HVT, Kwak K, Lee KK. 1,1-Dimethylpyrrolidinium tetrafluoroborate as novel salt for high-voltage electric double-layer capacitors. Electrochim Acta, 2019, 299: 98-106

82 Yu X, Ruan D, Wu C, et al. Spiro-(1,1')-bipyrrolidinium tetrafluoroborate salt as high voltage electrolyte for electric double layer capacitors. J Power Sources, 2014, 265: 309-316

83 Shi M, Kou S, Yan X. Engineering the electrochemical capacitive properties of graphene sheets in ionic-liquid electrolytes by correct selection of anions. ChemSusChem, 2014, 7: 3053-3062

84 Drüschler M, Huber B, Passerini S, et al. Hysteresis effects in the potential-dependent double layer capacitance of room temperature ionic liquids at a polycrystalline platinum interface. J Phys Chem C, 2010, 114: 3614-3617

85 El-Kady MF, Strong V, Dubin S, et al. Laser scribing of highperformance and flexible graphene-based electrochemical capacitors. Science, 2012, 335: 1326-1330

86 Zhang Q, Yang H, Lang X, et al. 1-Ethyl-2,3-dimethylimidazolium tetrafluoroborate ionic liquid mixture as electrolyte for highvoltage supercapacitors. Ionics, 2019, 25: 231-239

87 Zhu Y, Murali S, Stoller MD, et al. Carbon-based supercapacitors produced by activation of graphene. Science, 2011, 332: 15371541

88 Pohlmann S, Kühnel RS, Centeno TA, et al. The influence of anion-cation combinations on the physicochemical properties of advanced electrolytes for supercapacitors and the capacitance of activated carbons. ChemElectroChem, 2014, 1: 1301-1311

89 Schütter C, Neale AR, Wilde $\mathrm{P}$, et al. The use of binary mixtures of 1-butyl-1-methylpyrrolidinium bis\{(trifluoromethyl)sulfonyl\} imide and aliphatic nitrile solvents as electrolyte for supercapacitors. Electrochim Acta, 2016, 220: 146-155

90 Lee JH, Ryu JB, Lee AS, et al. High-voltage ionic liquid electrolytes based on ether functionalized pyrrolidinium for electric double-layer capacitors. Electrochim Acta, 2016, 222: 1847-1852

91 Han T, Park MS, Kim J, et al. The smallest quaternary ammonium salts with ether groups for high-performance electrochemical double layer capacitors. Chem Sci, 2016, 7: 1791-1796

92 Zhou ZB, Matsumoto H, Tatsumi K. Cyclic quaternary ammonium ionic liquids with perfluoroalkyltrifluoroborates: Synthesis, characterization, and properties. Chem Eur J, 2006, 12: 2196- 
2212

93 Rennie AJR, Sanchez-Ramirez N, Torresi RM, et al. Ether-bondcontaining ionic liquids as supercapacitor electrolytes. J Phys Chem Lett, 2013, 4: 2970-2974

94 Huang HC, Yen YC, Chang JC, et al. An ether bridge between cations to extend the applicability of ionic liquids in electric double layer capacitors. J Mater Chem A, 2016, 4: 19160-19169

95 Matsumoto M, Shimizu S, Sotoike R, et al. Exceptionally high electric double layer capacitances of oligomeric ionic liquids. J Am Chem Soc, 2017, 139: 16072-16075

96 Lian C, Su H, Liu H, et al. Electrochemical behavior of nanoporous supercapacitors with oligomeric ionic liquids. J Phys Chem C, 2018, 122: 14402-14407

97 Mousavi MPS, Wilson BE, Kashefolgheta S, et al. Ionic liquids as electrolytes for electrochemical double-layer capacitors: Structures that optimize specific energy. ACS Appl Mater Interfaces, 2016, 8: 3396-3406

98 Wang X, Li Y, Lou F, et al. Enhancing capacitance of supercapacitor with both organic electrolyte and ionic liquid electrolyte on a biomass-derived carbon. RSC Adv, 2017, 7: 23859-23865

99 Arbizzani C, Biso M, Cericola D, et al. Safe, high-energy supercapacitors based on solvent-free ionic liquid electrolytes. J Power Sources, 2008, 185: 1575-1579

100 Wang X, Mehandzhiyski AY, Arstad B, et al. Selective charging behavior in an ionic mixture electrolyte-supercapacitor system for higher energy and power. J Am Chem Soc, 2017, 139: 1868118687

101 Lian C, Liu K, Van Aken KL, et al. Enhancing the capacitive performance of electric double-layer capacitors with ionic liquid mixtures. ACS Energy Lett, 2016, 1: 21-26

102 Van Aken KL, Beidaghi M, Gogotsi Y. Formulation of ionic-liquid electrolyte to expand the voltage window of supercapacitors. Angew Chem, 2015, 127: 4888-4891

103 Zhang L, Yang X, Zhang F, et al. Controlling the effective surface area and pore size distribution of $\mathrm{sp}^{2}$ carbon materials and their impact on the capacitance performance of these materials. J Am Chem Soc, 2013, 135: 5921-5929

104 Xia J, Chen F, Li J, et al. Measurement of the quantum capacitance of graphene. Nat Nanotech, 2009, 4: 505-509

105 Zhu Y, Murali S, Cai W, et al. Graphene and graphene oxide: Synthesis, properties, and applications. Adv Mater, 2010, 22: 3906-3924

106 Pope MA, Aksay IA. Four-fold increase in the intrinsic capacitance of graphene through functionalization and lattice disorder. J Phys Chem C, 2015, 119: 20369-20378

107 Yadav N, Singh MK, Yadav N, et al. High performance quasisolid-state supercapacitors with peanut-shell-derived porous carbon. J Power Sources, 2018, 402: 133-146

108 Pal P, Ghosh A. Solid-state gel polymer electrolytes based on ionic liquids containing imidazolium cations and tetrafluoroborate anions for electrochemical double layer capacitors: Influence of cations size and viscosity of ionic liquids. J Power Sources, 2018, 406: $128-140$

109 Richey FW, Dyatkin B, Gogotsi Y, et al. Ion dynamics in porous carbon electrodes in supercapacitors using in situ infrared spectroelectrochemistry. J Am Chem Soc, 2013, 135: 12818-12826

110 Ko J, Kim YJ, Kim YS. Self-healing polymer dielectric for a high capacitance gate insulator. ACS Appl Mater Interfaces, 2016, 8: 23854-23861

111 Muchakayala R, Song S, Wang J, et al. Development and super- capacitor application of ionic liquid-incorporated gel polymer electrolyte films. J Indust Eng Chem, 2018, 59: 79-89

112 Sato T, Marukane S, Morinaga T, et al. High voltage electric double layer capacitor using a novel solid-state polymer electrolyte. J Power Sources, 2015, 295: 108-116

113 Singh R, Bhattacharya B, Gupta M, et al. Electrical and structural properties of ionic liquid doped polymer gel electrolyte for dual energy storage devices. Int J Hydrogen Energy, 2017, 42: 1460214607

114 Yang X, Zhang F, Zhang L, et al. A high-performance graphene oxide-doped ion gel as gel polymer electrolyte for all-solid-state supercapacitor applications. Adv Funct Mater, 2013, 23: 33533360

115 Feng L, Wang K, Zhang X, et al. Flexible solid-state supercapacitors with enhanced performance from hierarchically graphene nanocomposite electrodes and ionic liquid incorporated gel polymer electrolyte. Adv Funct Mater, 2018, 28: 1704463

116 Pandey GP, Liu T, Hancock C, et al. Thermostable gel polymer electrolyte based on succinonitrile and ionic liquid for highperformance solid-state supercapacitors. J Power Sources, 2016, 328: 510-519

117 Zhang X, Kar M, Mendes TC, et al. Supported ionic liquid gel membrane electrolytes for flexible supercapacitors. Adv Energy Mater, 2018, 8: 1702702

118 Jin M, Zhang Y, Yan C, et al. High-performance ionic liquidbased gel polymer electrolyte incorporating anion-trapping boron sites for all-solid-state supercapacitor application. ACS Appl Mater Interfaces, 2018, 10: 39570-39580

119 Ayalneh Tiruye G, Muñoz-Torrero D, Palma J, et al. All-solid state supercapacitors operating at $3.5 \mathrm{~V}$ by using ionic liquid based polymer electrolytes. J Power Sources, 2015, 279: 472-480

120 Liu Y, Zhao J, He F, et al. Influence of alkyl spacer length on ion transport, polarization and electro-responsive electrorheological effect of self-crosslinked poly(ionic liquid)s. Polymer, 2019, 171: 161-172

121 Trigueiro JPC, Lavall RL, Silva GG. Supercapacitors based on modified graphene electrodes with poly(ionic liquid). J Power Sources, 2014, 256: 264-273

122 de Oliveira PSC, Alexandre SA, Silva GG, et al. PIL/IL gel polymer electrolytes: The influence of the IL ions on the properties of solid-state supercapacitors. Eur Polymer J, 2018, 108: 452-460

Acknowledgements This work was supported by the National Natural Science Foundation of China (21373118, 21573112, 21421001 and 21703108).

Author contributions Yin $\mathrm{L}$ and Yan $\mathrm{T}$ conceived and wrote the manuscript and designed the figures. Liu $\mathrm{X}$ and $\mathrm{Li} \mathrm{S}$ revised the manuscript. All authors contributed to the general discussion and revision of the manuscript.

Conflict of interest The authors declare no conflict of interest.

Supplementary information Supporting data are available in the online version of the paper. 


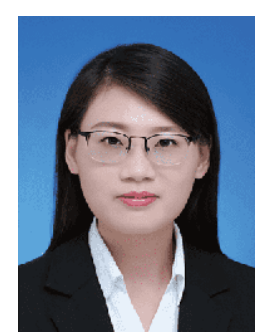

Li Yin earned her $\mathrm{PhD}$ degree from Nankai University in 2018. She is currently performing postdoctoral research in the Institute of New Energy Chemistry, School of Materials Science and Engineering, National Institute for Advanced Materials, Nankai University, Tianjin. Her current research focuses on the capacitive performance of ionic liquid electrolytes applied in EDLCs.

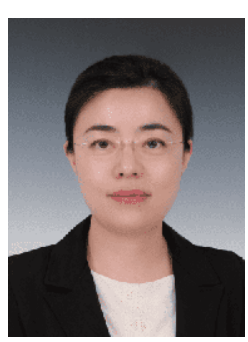

Shu Li received her $\mathrm{PhD}$ degree from Nankai University (2010). She is currently a lecturer in the Institute of New Energy Chemistry, School of Materials Science and Engineering, National Institute for Advanced Materials, Nankai University, Tianjin. Her current research focuses on the IL electrolytes by molecular dynamic simulation.

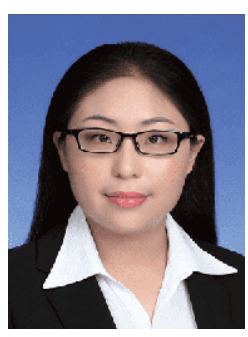

Xiaohong Liu received her $\mathrm{PhD}$ degree from Nankai University (2016). She is currently an experimentalist in the Institute of New Energy Chemistry, School of Materials Science and Engineering, National Institute for Advanced Materials, Nankai University, Tianjin. Her current research focuses on the ILs-based electrolytes in supercapacitors.

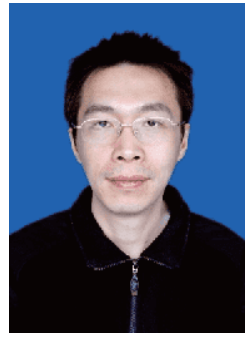

Tianying Yan obtained his $\mathrm{PhD}$ degree in 2003 from Wayne State University. He carried out postdoctoral research at the University of Utah and Henry Erying. Now he is a professor in the Institute of New Energy Chemistry, School of Materials Science and Engineering, National Institute for Advanced Materials, Nankai University, Tianjin. His research interests are devoted to ILs-based storage/conversion of energy in supercapacitors combined with experimental, theoretical and simulation techniques.

\section{离子液体电解液在双电层电容器中的研究}

尹莉, 李姝, 刘晓红 ${ }^{*}$, 言天英 ${ }^{*}$

摘要 双电层电容器(EDLCs)通过非法拉第过程在电极表面储存 自由电荷, 其通过电解质侧的双电层平衡, 具有优异的循环稳定性 和高功率密度. 虽然EDLC被认为是有前景的能量储存器件, 但其 电极表面存储的电荷远低于电池, 其较低的能量密度限制了其应 用. 离子液体(ILs), 因其较宽的电化学窗口和独特的物理化学性能, 可显著提高EDLCs的能量密度. 本文综述了纯ILs、IL/IL二元混合 体系、IL/有机溶剂混合体系以及功能化ILs等电解液, 着重探讨了 ILs的离子组成、尺寸、结构与电容的关系. 咪唑类和季铵盐类ILs 作为目前研究最广泛的两类ILs, 前者一般具有较高的重量比电容, 后者则表现出更宽的电化学窗口. 故可对季铵盐类ILs进行官能化 以提高其重量比电容, 进而提高EDLCs的能量密度. 